ANUARIO DE Estudios MEdIEVALES

43/1, enero-junio de 2013, pp. 199-242

ISSN 0066-5061

doi:10.3989/aem.2013.43.1.07

\title{
MEDICINA ANIMAL EN LA BAJA EDAD MEDIA HISPÁNICA Y SU RELACIÓN CON LA MEDICINA HUMANA: AVES, PERROS Y CABALLOS ${ }^{1}$
}

\author{
ANIMAL MEDICINE IN THE LATE MEDIEVAL IBERIAN PENINSULA \\ AND ITS RELATIONSHIP WITH HUMAN MEDICINE: \\ BIRDS, HOUNDS AND HORSES
}

\author{
RICARDO M. OLMOS DE LEÓN
}

Universitat de València

\begin{abstract}
Resumen: El alto valor económico y social de halcones, perros y caballos en la baja Edad Media hizo que se desarrollara una práctica médica especializada para matenerlos sanos y curarlos de sus enfermedades. De forma paralela, una producción de obras técnicas codificó estos conocimientos médicos creando un cuerpo doctrinal específico. A partir del análisis de dichos tratados pueden establecerse estrechas relaciones con la doctrina médica vigente -el galenismo-, que van más allá de compartir la teoría humoral y la de las cualidades. La importancia de preservar la salud y las herramientas conceptuales para hacerlo, la prioridad de la dieta como recurso terapéutico sobre el medicamento o la cirugía, el principio de curar por el contrario, las técnicas de evacuación de humores, el examen de superfluidades para diagnosticar enfermedades o el empleo de las mismas medicinas, son algunos de los aspectos en los que médicos, albéitares, halconeros y cazadores estuvieron de acuerdo.
\end{abstract}

Palabras clave: medicina medieval; medicina animal; cetrería; albeitería; perros.

\begin{abstract}
The high economic and social value of falcons, hounds and horses in the late Middle Ages led to the development of a specialized medical practice to keep them healthy and treat their diseases. A parallel production of technical works coded this medical knowledge, generating a specific doctrinal body. From the analysis of these treatises it is possible to find close relationships with the current medical doctrine -galenism-, that go beyond the sharing of theories on humors and qualities. The importance of maintaining health and the conceptual instruments to achieve this aim, the precedence of diet as a therapeutic tool over drugs or surgery, treating by applying opposite, techniques of humor evacuation, examination of superfluities as diagnostic tool for diseases and the use of the same drugs are some of the aspects on which physicians, hippiatrists, falconers and huntsmen agreed.
\end{abstract}

Keywords: medieval medicine; animal medicine; falconry; hippiatry; hounds.

\footnotetext{
${ }^{1}$ Este trabajo se enmarca dentro de la investigación de doctorado del autor del artículo sobre la medicina de las aves de caza en la Baja Edad Media a partir de los tratados castellanos de cetrería.
} 


\section{SUMARIO}

1. Introducción.- 2. Medicina de los animales y galenismo.- 2.1. La conservación de la salud.-2.2. Enfermedades de los animales y su cura.-3. Los mismos remedios para los mismos males.- 3.1. Las enfermedades de los ojos y su cura.- 3.2. La sarna y su tratamiento.- 4. Conclusiones.- 5. Bibliografía citada.

\section{INTRODUCCIÓN}

El caballo, el perro y el halcón, compañeros inseparables de los nobles en sus partidas de caza, ocuparon un papel destacado entre los animales que convivieron con el hombre durante la Edad Media. Imprescindible para la guerra, el caballo jugó, junto a sus parientes -mulas y asnos- un papel fundamental como fuerza de trabajo. El halcón, además de su insustituible valor como auxiliar en la caza, se convirtió en símbolo de nobleza y elemento de distinción social, lo que llevó a este animal a ser codiciado por todos aquellos miembros de la sociedad que veían en la nobleza un modelo a imitar. En fin, el perro, adaptándose a la categoría de su amo, buscó y acosó al jabalí en grandes monterías reales, ayudó al halcón del clérigo para capturar la garza y persiguió al conejo en compañía de su más modesto dueño.

Así, estos tres animales llegaron a tener en la baja Edad Media un alto valor económico y simbólico que llevó a que sus propietarios recurrieran a personas expertas con conocimientos específicos con el fin de que los cuidaran y los adiestraran para el cometido que se les asignaba. De este modo, albéitares, halconeros y cazadores asumieron, entre sus responsabilidades, la conservación de la salud y la cura de las enfermedades de los animales que les habían sido encomendados. La importancia y la dificultad de dicha tarea pueden justificar la proliferación, durante la baja Edad Media, de los tratados de hipología y de caza, en los que gran parte del contenido se dedicó a la hipiatría y a los cuidados de las aves de cetrería, respectivamente. Además de la importancia para el caballero, quien debía contar con el caballo que su condición le exigía para la guerra, los equinos -asnos, mulas y caballosconstituyeron un pilar de la economía bajomedieval como fuerza de trabajo. Esta importancia que las caballerías tuvieron en la sociedad fue lo que llevó a que la pericia del albéitar, a menudo unida a la de herrador, tuviera que extenderse más allá de las caballerizas señoriales y fuera necesaria para atender a las bestias enfermas de toda una ciudad. Pero, ¿tenía esta atención médica que se prestaba a los animales una fundamentación teórica? En caso afirmativo, ¿cuál era esta doctrina subyacente y qué relación tenía con la ciencia médica bajomedieval? 
Gracias a los estudios llevados a cabo durante el último siglo sobre la medicina de los animales -especialmente equinos y aves de presa- en la actualidad contamos con un panorama general de la actividad de curar animales en la Edad Media ${ }^{2}$. La aproximación de veterinarios, filólogos e historiadores ha permitido que dispongamos de ediciones críticas de muchos de los tratados de hipología y de caza medievales y que conozcamos con bastante detalle su contenido patológico y terapéutico ${ }^{3}$. Sin embargo, ha sido más recientemente cuando se ha empezado a llamar la atención sobre la necesidad de interpretar dichos contenidos en el contexto científico de la época y determinar la relación que pudiera existir con la doctrina que sustentaba la práctica de la atención médica a las personas, el galenismo ${ }^{4}$. Resulta pues, oportuno, superar el planteamiento de hacer corresponder los males que padecían los animales en la Edad Media con las enfermedades que reconoce la veterinaria moderna y de intentar evaluar con los conocimientos científicos actuales la posible eficacia de los tratamientos prescritos en las obras medievales 5 .

La vertiente práctica y social de la medicina de los animales $-\mathrm{y}$ en concreto, los aspectos relacionados con el cuidado de aquellos de gran valor económico y social, como fueron aves de caza, perros y caballos- han empezado recientemente a ser objeto de estudio ${ }^{6}$. Especialmente en el ámbito del cuidado de los equinos, la transmisión de los conocimientos y la formación de los albéitares, su lugar en la sociedad o la regulación de su actividad, son aspectos que empezamos a conocer gracias a investigaciones recientes basa-

\footnotetext{
${ }^{2}$ En el ámbito de las facultades de veterinaria alemanas, desde el primer tercio del siglo pasado, se defendieron numerosas tesis doctorales sobre textos de albeitería o cetrería de época medieval o moderna. Algunas de estas tesis sobre el cuidado de las aves de cetrería son Falkenheilkunde, de P. Kraenner, Die Falkenheilkunde des kurfürstlichen Amtmannes Johann Wolff aus Mündelsheim (1584), de H. Czapalla y Beitrag zur Entwicklung der Falknerei und der Falkenheilkunde, de A. Gerdessen. Sobre el cuidado de los equinos: Die Pferdeheilkunde des Jordanus Ruffus, de R. Roth, Die Pferdeheilkunde des Bischofs Theodoric von Cervia, de W. Heinemeyer y Die Pferdeheilkunde des Cosimo Marci Medici, de K.-H. Möckel. En España, los trabajos más significativos relacionados con la medicina de las aves, perros y caballos, realizados desde la perspectiva de la veterinaria, son los de C. Sanz Egaña: Noticias de la medicina de los animales y Historia de la veterinaria española.

${ }^{3}$ Los contenidos médicos de los tratados medievales de hipiatría pueden verse en Y. Poulle-Drieux, L'hippiatrie, pp. 51-114. Para el caso de las aves y perros de caza, véase A. von den Driesch, J. Peters, Geschichte der Tiermedizin, pp. 101-109. Para la literatura medieval sobre los cuidados de los perros, véase B. Van den Abeele, J. Loncke, Les traités médiévaux, pp. 281-296.

${ }^{4} \mathrm{El}$ interés de determinar la relación entre la medicina de las aves de cetrería y la medicina humana ya fue puesta de manifiesto en B. Van den Abeele, La fauconnerie, pp. 210-213.

${ }^{5}$ A menudo, este enfoque está presente en las investigaciones de veterinarios y filólogos. Para el caso de las aves de cetrería, puede verse este planteamiento en B. Van den Abeele, La fauconnerie, pp. 173-260, o en A. Smets, Aux origines de la médecine vétérinaire, pp. 149-153.

${ }^{6}$ En Y. Poulle-Drieux, La médecine des chevaux, pp. 12-22, se plantean cuestiones como la transmisión de los conocimientos y la relación con la medicina humana.
} 
das, principalmente, en documentos de $\operatorname{archivo}^{7}$. La práctica real del cuidado de los animales y su mayor o menor correspondencia con la doctrina recogida en los tratados también ha sido una cuestión planteada recientemente por la investigación histórica y, pese a haberse centrado casi exclusivamente en las caballerías, los resultados son prometedores y constituyen una guía para posteriores investigaciones relacionadas con aves o perros ${ }^{8}$.

En el presente trabajo analizamos de forma conjunta las relaciones de la medicina de halcones, perros y caballos con la medicina humana en la baja Edad Media. La decisión de considerar estos tres grupos de animales se justifica por las características que compartieron. En primer lugar, el hecho de que el cuidado de cada uno de estos grupos de animales estuviera asignado a un personal especializado -albéitares, halconeros, cazadores-, con una formación y unas cualidades adecuadas para ello. En segundo lugar, que en todos los casos se desarrollara una literatura específica para recoger los conocimientos que requería el arte de cuidar los animales, por más que en el caso de los canes esta literatura sea mucho más reducida. En tercer lugar, que aves, perros y caballos habitaron en el entorno de los estamentos sociales superiores de la sociedad, lo que situó la práctica médica asociada a estos animales dentro del entorno social en el que se desarrolló el sistema médico conocido como galenismo. Por otra parte, el estudio conjunto de la doctrina médica relacionada con cada uno de estos tres grupos de animales nos permite descubrir relaciones entre las mismas, además de las que pudieron existir con la medicina humana.

No es nuestra intención analizar todo el corpus doctrinal para exponer de forma exhaustiva los contenidos médicos de los tratados de hipología, cetrería y caza sino, más bien, señalar y poner de relieve los múltiples aspectos comunes a la doctrina médica en que se basaban los cuidados de estos animales y de los humanos. Para ello hemos centrado nuestro análisis en los principales tratados de albeitería, cetrería y caza que circularon por los reinos hispánicos hacia el fin de la Edad Media9.

\footnotetext{
${ }^{7}$ C. Ferragud, La cura dels animals, pp. 40-64 y 90-96, y C. Ferragud, La atención médica de los animales, pp. 33-46.

${ }^{8}$ Y. Poulle-Drieux, Pratique de l'hippiatrie, pp. 331-336; C. Ferragud, La cura dels animals, pp. 64-75.

${ }^{9}$ Las obras de medicina de los caballos de referencia para este estudio son el tratado anónimo del siglo XIII editado con el título El libro de los caballos y su traducción catalana editada como Lo libre dels cavayls, la compilación catalana basada en la obra de Giordano Ruffo y editada con el título Lo cavall y el Llibre de menescalia de Manuel Díez (en sus ediciones castellana y catalana). Información sobre estas obras en el contexto de la literatura hipiátrica puede consultarse en L. Cifuentes, C. Ferragud, El 'Libre de la Menescalia' de Manuel Dies, pp. 99-100, además del estudio clásico de referencia, en Y. Poulle-Drieux, L’hippiatrie, pp. 15-48. Los textos de medicina de las aves consultados son los tratados de cetrería castellanos Libro de los animales que cazan, traducción del Kitāb al-Ŷawārih de Muhammad ibn 'Abd Allāh ibn 'Umar al-Bayzār, el Libro de la caza, de Juan Manuel, el Libro de la caza de las aves, de Pero López de
} 


\section{MEDICINA DE LOS ANIMALES Y GALENISMO}

Tanto en los tratados bajomedievales de medicina animal como en los de medicina humana se encuentran menciones explícitas a una naturaleza animal y humana basada en un sistema común de cuatro humores ${ }^{10}$, uno de los pilares de la doctrina médica conocida como galenismo. Sin embargo, el análisis de los textos medievales que recopilaron y expusieron los conocimientos sobre el cuidado de los animales muestra que en ellos existen muchos más elementos propios de ese sistema médico medieval que fue el galenismo. Ello sugiere que debieron existir unas estrechas relaciones, tanto en el ámbito doctrinal como en el de la práctica, entre la medicina humana y la medicina de los animales.

\subsection{La conservación de la salud}

Un primer aspecto en el que encontramos un estrecho paralelismo entre la medicina animal y la medicina humana bajomedievales es la posición destacada que presenta la salud, tanto de bestias como de personas ${ }^{11}$. Si el contenido de los tratados latinos de cetrería es básicamente terapéutico y pueden considerarse, en gran medida, como recopilación de recetas para tratar diferentes enfermedades ${ }^{12}$, a partir del siglo XIII, con la aparición de los textos en lenguas vernáculas -traducciones del árabe o tratados originalesse modificó significativamente su estructura y contenidos incluyendo, entre

Ayala y el Libro de las aves que cazan, de Juan de Sahagún. Información detallada sobre ellos y sobre la literatura cetrera castellana puede consultarse en J.M. Fradejas, Literatura cetrera, pp. 13-38. También se ha revisado para este estudio el tratado anónimo catalán de cetrería Libre de animals de caçar (Ms. 505 de la Biblioteca Histórica de la Universidad de Valencia). Para la medicina de los perros, el estudio se ha basado en la sección correspondiente del Libro de los animales que cazan, el Livro da montaria, de Juan I de Portugal, el De cane, de Alberto Magno y las recetas para enfermedades de los perros contenidas en los manuscritos Libre de animals de caçar y Libre dels oçells de caça (Ms. 68 de la Universidad de Barcelona). Ocasionalmente se ha recurrido a otros tratados, que son citados oportunamente. En las citas textuales de obras editadas se ha mantenido el texto tal y como aparece en la edición de referencia.

${ }^{10}$ Entre los tratados de medicina humana, el Pantegni de Haly Abbas explica: "omnia ergo membra humana sive bestialia sanguinem habentia ex quattuor humoribus sunt facta .i. de sanguine, cholera, phlegmata et melancolía" ("Alī ibn al-"Abbās, Liber Pantegni, f. 4v); en términos muy parecidos se describe la naturaleza de las aves en un tratado árabe medieval de cetrería: "Dios creó al hombre a partir cuatro naturalezas: sangre, bilis amarilla, flema y bilis negra. (...) El azor y el resto de las aves de caza también han sido creados de las cuatro naturalezas" (al-Baladī, Kitāb al-kāfì p. 201).

${ }^{11}$ L. García Ballester, La búsqueda de la salud, pp. 145-159.

${ }^{12}$ Debe hacerse excepción del De arte venandi cum avibus, de Federico II. Sobre el contenido de los tratados latinos de cetrería, véase B. Van den Abeele, La fauconnerie, pp. 261-266. 
otras novedades, informaciones específicas destinadas a la conservación de la salud, a evitar la enfermedad antes de que apareciera ${ }^{13}$. Estas informaciones pueden encontrarse, bien dispersas a lo largo de la obra, bien agrupadas en uno o varios capítulos destinados al regimiento del ave de caza. Los tratados de hipología, del mismo modo, presentan diferentes capítulos con los cuidados y atenciones requeridos para conservar la salud de los caballos u otros equinos ${ }^{14}$. Por último, no falta en aquellos tratados de cetrería o de caza que contienen alguna sección o capítulo sobre los perros, información con indicaciones para mantener a los canes sanos ${ }^{15}$. Prueba también de la importancia que se concedía a la salud de los animales es que las obras relacionadas con cada uno de estos grupos -aves, perros y caballos- también incluyeron la información pertinente para reconocer al animal sano antes de adquirirlo o escogerlo ${ }^{16}$.

Este interés explícito por la conservación de la salud de los animales parece reflejo de un interés similar existente en el ámbito de la medicina humana, puesto de manifiesto por la proliferación, a partir del siglo XIII, de los regimina sanitatis. Este género médico, muy desarrollado dentro del galenismo latino occidental, consistía en la prescripción de una serie de pautas para regular los diferentes aspectos de la vida, con el objetivo de conservar la salud de determinados individuos o del ser humano en general. El contenido de estos regímenes de salud se articulaba habitualmente alrededor de las sex res non naturales, que eran aquellos factores que, sin ser elementos constituyentes del organismo (res naturales), influyen en la salud de las personas y de los seres vivos y que el galenismo fijó en seis: el aire, el ejercicio -a menudo asociado con el baño-, la alimentación, el sueño, la evacuación y las emociones. Una adecuada observación de las pautas establecidas en el regimen sanitatis permitía conservar la salud, mientras que el incumplimiento de los preceptos se constituía en causa de enfermedad ${ }^{17}$.

Como veremos a continuación, las obras medievales que se ocuparon de la atención médica a animales valiosos como aves, perros o caballos, pese

\footnotetext{
${ }_{13}^{13}$ J.M. Fradejas, Literatura cetrera, pp. 7-12.

${ }^{14}$ Por ejemplo, un tratado de albeitería contiene dicha información en los capítulos: "Com deu ésser guardat o fermat lo cavall", "Com deu ésser donada la erba al cavall en sa porga" y "Del cavall. En quina manera li és conservada sanitat" (J. Gili (ed.), Lo cavall, pp. 22-30 y 42-44). La importancia de los cuidados orientados a conservar la salud en los caballos ya había sido destacada en Y. Lignereux, Les soins vétérinaires aux chevaux, pp. 46-47.

${ }^{15}$ Muhammad b. 'Abd Allāh, Libro de los animales que cazan, pp. 222-226.

${ }^{16}$ Consejos para elegir el ave pueden verse en M. Delgado, Edición crítica, pp. 153-156. Indicaciones para elegir adecuadamente el caballo se encuentran en J. Gili (ed.), Lo cavall, pp. 38-41; algunas de éstas están relacionadas con las aptitudes y cualidades del caballo y otras con su salud y sus enfermedades.

${ }^{17}$ Sobre los tipos de regimina sanitatis, su contenido y estructura, véase P. Gil-Sotres, Regimen sanitatis, pp. 513-563.
} 
a no nombrar explícitamente a las seis cosas no naturales, se refirieron a todos estos factores en sus contenidos higiénicos orientados a conservar la salud de dichos seres ${ }^{18}$. Del mismo modo, en las secciones terapéuticas de los tratados, algunas de las seis cosas no naturales aparecen explícitamente como causas de determinadas enfermedades.

Un aspecto interesante del contenido sobre higiene de los animales en los tratados es que, al igual que sucedía en los regimina sanitatis, suelen incluir pautas específicas para las diferentes circunstancias que en éstos se daban. Además de las particularidades de los cuidados de los equinos jóvenes, algunos tratados de albeitería distinguían el régimen estival del régimen invernal para las caballerías o las diferentes condiciones en que debían tenerse los caballos en tiempo de paz y en tiempo de guerra ${ }^{19}$. Por lo que respecta a los tratados de cetrería, todos distinguieron los requerimientos particulares necesarios para conservar la salud de las aves durante la muda frente al régimen del resto del año, periodo en el que las aves eran empleadas para la caza ${ }^{20}$.

Referencias a la primera de las sex res non naturales, el aire, encontramos en el régimen higiénico de diferentes tratados de cetrería, de albeitería y de caza. Conviene recordar que el aire, como res non natural, incluía no solo el aire propiamente dicho, sino también el alojamiento, la vestimenta y todo lo que rodea físicamente al animal o la persona. En los tratados de cetrería es habitual encontrar indicaciones sobre cómo debían construirse las mudas de las aves, indicando a menudo la orientación que debían tener, por dónde debía entrar el sol y el viento e, incluso, la conveniencia de colocar en su interior plantas aromáticas que purificaran el aire ${ }^{21}$. Casi todos los autores coincidían en la importancia de la ausencia de humo, polvo, sereno y malos olores, haciendo a estos elementos responsables de algunas enfermedades

\footnotetext{
${ }^{18}$ El carácter práctico de las obras de caza y de hipología debió ser la razón de que en dichos tratados la exposición y explicación teóricas se vieran reducidas, resultando muy pobres en comparación con las encontradas en los tratados de medicina humana.

${ }^{19}$ L. Faraudo (ed.), El texto primitivo inédito, p. 31, y M. Dieç, Tractat, ff. 11v-14v.

${ }^{20}$ Durante el periodo de muda, que se prolongaba durante varios meses en primavera y verano, las aves renovaban su plumaje y eran mantenidas en cámaras llamadas "mudas", sin emplearlas para cazar ni hacerlas volar. Las exigencias fisiológicas de la renovación del plumaje exigía unos cuidados específicos que todos los autores de tratados de cetrería distinguieron de los cuidados requeridos por las aves durante el resto del año. Por ejemplo, Juan Manuel, en su Libro de la caza, dedicó el capítulo 12 al régimen higiénico de la muda de las aves (J.M. Fradejas (ed.), Don Juan Manuel, pp. 173-177).

${ }^{21}$ Ibidem, pp. 173-177; Muhammad b. 'Abd Allāh, Libro de los animales que cazan, pp. 81-94; M. Delgado, Edición crítica, pp. 407-409. Sobre los olores y el aire en los regimina sanitatis, véase P. Gil-Sotres, Regimen sanitatis, pp. 574-580. La purificación con plantas aromáticas del aire de la muda se recomienda en Muḥammad b. 'Abd Allāh, Libro de los animales que cazan, p. 83.
} 
$\operatorname{concretas}^{22}$. Además, la exposición al sol o a determinados vientos debía regularse también para mantener a las aves sanas. Del mismo modo que determinadas vestimentas podían tener efectos beneficiosos o perjudiciales para la salud de las personas ${ }^{23}$, la salud de los animales también podía beneficiarse de un adecuado uso de determinadas prendas, como puede leerse en la recomendación del canciller Pero López de Ayala: ponle sienpre la lúa deyuso de los pies, que sea blanda, o un paño de color atado a la vara ca le es muy sano para los pies $^{24}$. Por supuesto, al igual que en el caso de las personas, el régimen higiénico dependía de la complexión y, por tanto, del ave de que se tratara, por lo que algunas condiciones eran necesarias o adecuadas para unas aves y no para otras ${ }^{25}$.

También los tratados de caza, refiriéndose a los perros, proporcionaron indicaciones sobre cómo los an atar e en qué logares an de yazer. Aconsejaban atarlos lejos unos de otros ca el estar que están unos cerca dotros les faze oler mal los fuelgos e los faze ensarneçer e les faze aver muchas denfermedades. Además, al igual que en el caso de los halcones, era conveniente que en aquellos logares ó yoguieren póngales ý ropa o otra cosa blanda ${ }^{26}$.

La salud de las caballerías dependía igualmente del lugar y las condiciones en que se alojaban. Así, Manuel Díez recomendaba que deveu tanir la mula en loc que no sia calt ne gayre ffret, e tinga palla exuta en que yague. E no la tingau a la sarena ni en loch que li do vent ${ }^{27}$. En el tratado de albeitería Lo cavall se destacaba que

\footnotetext{
${ }^{22}$ Por ejemplo, para el halcón se recomendaba: "guárdalo de le dar sereno de noche o fumo o mala vianda e así nunca se cargará de agua para que lo ayas de melezinar" (M. Delgado, Edición crítica, p. 222). Juan Manuel ponía el énfasis en los olores: "et dévenlos guardar que los non pongan en nungún lugar do aya olor de vino nin de vinagre nin do aya albergado ganado nin do haya ningund mal olor [nin] en casa úmida" (J.M. Fradejas (ed.), Don Juan Manuel, p. 164).

${ }^{23}$ P. Gil-Sotres, Regimen sanitatis, pp. 583-590.

${ }^{24}$ M. Delgado, Edición crítica, p. 176. En el caso de los caballos, también se recomendaba cubrirlos con mantas de diferentes tejidos, según requiriera la ocasión; véase J. Gili (ed.), Lo cavall, pp. 29-30.

${ }^{25}$ Por ejemplo, el emplazamiento y los requisitos de la muda (cámara donde se alojaban las aves, especialmente durante el periodo de cambio de plumaje) eran diferentes para las distintas aves: "Otrosí las mudas de los girifaltes deve ser en la más tierra fría que pudieren fallar", pero "a los sacres que son tomados bravos dévenles mudar et fazer las mudas bien así como a los girifaltes, salvo ende porque non an por qué fazer tan grant fuerça en buscarles tierra tan fría para en que les fagan las mudas. Otrosí deven fazer en esa misma guisa a los neblís. Mas los baharís se deven mudar en casa do entre el sol et que sea bien lumbrosa et deven andar sueltos et quantos más mudaren en uno, tanto mudarán mejor.” (J.M. Fradejas (ed.), Don Juan Manuel, pp. 175-177).

${ }^{26}$ Muhammad b. 'Abd Allāh, Libro de los animales que cazan, p. 224.

${ }^{27}$ L. Faraudo (ed.), El texto primitivo inédito, p. 9.
} 
moltes diverses de malalties són engendrades al cavayll per la babor del estable, per què és mester que covinentea e en temprança cascun temps sia tengut, e deu éser donada cura que el fe o la palla no haja mala hodor ne si[a] corrumpuda, ans totes cosses ben ollents,

concordando con la interpretación médica de los buenos y malos olores dada en los regímenes de salud ${ }^{28}$.

La segunda res non natural, el ejercicio ${ }^{29}$, que habitualmente se presentaba en forma de extremos opuestos de un continuo -movimiento y reposo-, también aparece en los tratados de cetrería, albeitería y caza como otro de los factores a tener en cuenta para conservar la salud de los animales, así como causa de determinadas enfermedades. En el caso de las aves, el ejercicio tenía lugar principalmente con el vuelo. Por ello, en ocasiones se recomendaba que el día en que, por alguna razón, el ave no fuera a cazar, se sacara a volar al señuelo ${ }^{30}$. En cualquier caso, la importancia que se atribuía al ejercicio para conservar la salud se pone claramente de manifiesto al considerar la falta de éste como una de las principales causas de enfermedad en las aves de caza ${ }^{31}$.

También en el caso de los caballos y de los perros encontramos referencias a la influencia del ejercicio en la salud. Y es que, al igual que lo que se planteaba para las personas, tan negativo para la salud podía ser la falta de ejercicio como el exceso de éste. En el tratado Lo cavall, en relación con esta res non natural, se recordaba que cavall ben guardat e tempradament cavalcat, en la sua virtut e en la sua bonea cuax en lo demés dura per spay de .xx. ayns, e encara més segons la sua calytat ${ }^{32}$. Algunos textos de albeitería y de caza hacen responsables de la aparición de sarna en caballos y perros al exceso de ejercicio (segunda res non natural) además de otros factores como el frío y las condiciones del alojamiento (primera res non natural) ${ }^{33}$.

${ }^{28}$ J. Gili (ed.), Lo cavall, p. 43.

${ }^{29}$ Sobre el ejercicio y el baño en los regimina sanitatis, véase P. Gil-Sotres, Regimen sanitatis, pp. 599-643.

${ }^{30}$ El señuelo era el armadijo de cuero y plumas que, atado a una cuerda, se hacía girar para llamar a los halcones. La acción de llamar al halcón con el señuelo para hacerle volar una larga distancia en línea recta se denominaba señolar a la tira: "el día que tu falcón non bolare en ribera o por otra prisión non olvides el señolar a la tira" (M. Delgado, Edición crítica, p. 189).

${ }^{31}$ Dice el canciller que los halcones "vienen muy entecados e dolientes (...) otrosí porque vienen en el navío mal traídos e quebrantados de la mar e han estado gran tienpo presos sin bolar" (M. Delgado, Edición crítica, pp. 152-153).

${ }^{32}$ J. Gili (ed.), Lo cavall, p. 30.

${ }^{33}$ Véase, más adelante en este artículo, en las causas de la sarna en perros y caballos. 
El baño fue incluido entre las seis cosas no naturales, pese a que su ubicación en el esquema no fue la misma para todos los autores medievales. El galenismo latino colocó casi siempre el baño junto al ejercicio, por su papel complementario en la eliminación de residuos asociada a la actividad física. En cualquier caso, este aspecto también fue considerado por los responsables de los cuidados de los animales como un elemento a tener en cuenta para mantener a los animales sanos. Prácticamente todos los tratados de cetrería dan prescripciones sobre la necesidad de proporcionar el baño a las aves de caza, así como de su frecuencia y emplazamiento ${ }^{34}$. Durante el periodo de muda de las aves, que las llevaba a permanecer varios meses encerradas, era de suma importancia mantener el agua del baño limpia, recordándose que debía cambiarse regularmente para que no se corrompiera. Manuel Díez, para el cuidado de las mulas aconsejaba, para el invierno, feu la rebeyar ffins al ventre, mientras que en verano portau la a rebeyar e banyau la tota, e lo cap e tot l als, $e$ taniu la una estona en lo rabeig de la aygua ${ }^{35}$.

La tercera res non natural, la alimentación, es sin duda la más detallada en los tratados de albeitería y de caza. Las obras de cetrería proporcionan información sobre la carne para alimentar a las aves, distinguiendo los animales cuya carne es beneficiosa, de aquellos cuya carne es perjudicial como alimento de halcones y azores. Pero la salud del ave no dependía únicamente del animal que se empleaba como alimento, sino que la parte de dicho animal y la edad del mismo también eran características que debían ser tenidas en cuenta. Además, la complexión de las aves de caza -diferente en cada una-, la edad (jóvenes o adultas) o el hecho de encontrarse en periodo de muda o de caza, exigían una alimentación específica adecuada a esas circunstancias ${ }^{36}$. Algunos cazadores tenían en cuenta también la temperatura de la carne que daban como alimento a sus aves de cetrería o recomendaban el momento del día y el número de veces que se debía proporcionar ${ }^{37}$. En algún tratado, incluso, se desaconsejaba mezclar diferentes tipos de carnes en una comida ${ }^{38}$. Todas estas prescripciones que, de forma más o menos dispersa, se encuentran en los tratados de cetrería, concuerdan fielmente con muchas de las indicaciones dadas

${ }^{34}$ Por ejemplo, véase J.M. Fradejas (ed.), Don Juan Manuel, pp. 163-164.

${ }^{35}$ L. Faraudo (ed.), El texto primitivo inédito, p. 9.

${ }^{36}$ Especialmente detallados en este aspecto son los tratados árabes y de ahí que contemos en el Libro de los animales que cazan (traducción castellana de un tratado árabe) dos extensos capítulos sobre todos los aspectos de la alimentación (Muhammad b. 'Abd Allāh, Libro de los animales que cazan, pp. 32-41).

${ }^{37}$ M. Delgado, Edición crítica, pp. 170-171.

${ }^{38}$ J.M. Fradejas (ed.), Don Juan Manuel, p. 163; Muhammad b. 'Abd Allāh, Libro de los animales que cazan, pp. 32-39; M. Delgado, Edición crítica, pp. 92, 10-171, 188-190. 
en los regimina sanitatis medievales ${ }^{39}$. Por otra parte, no faltan en los libros de caza referencias a una mala alimentación como responsable de determinadas enfermedades ${ }^{40}$.

Que la salud de los perros de caza dependía del alimento que se les proporcionaba era algo claro para los cazadores medievales. El Libro de los animales que cazan dedicó un capítulo a la alimentación de los canes, indicando lo que se les debía dar, cuántas veces al día, en qué momento y en qué cantidad, teniendo en cuenta, además, la época del año. La importancia de la alimentación para la salud aparece de forma explícita en la advertencia de que lo que se contiene en dicho capítulo de cómo las an a dar a comer e cómo las an de engordecer, es una de las maneras por que las pueden guardar de las enfermedades que les acaeçen ${ }^{41}$. Por otra parte, el Livro da montaria de Juan I de Portugal proporciona una información muy interesante que demuestra que en la baja Edad Media, la preocupación por la salud y las enfermedades de los animales, incluidos los perros, originaba intensos debates. En el capítulo duodécimo del mencionado tratado, al referirse a la alimentación de los canes, se aclara que

sobre este gouuerno ouueron grande referta en departimento os monteyros sobre o criamento dos alaãos e sabuios, que uianda era milhor pera thes darem a comer quando fossem nouos e teuerom algũus que o leite era milhor comer que lhes poderiam dar. E outros algũus disserom que dando de comer aos alaãos quando fossem nouos carne, que este seria o milhor mantimento que lhes poderiam dar. E outros tiuerom que o pan seco lhes faria milhores corpos. Outros disserom que o pan no azeite era milhor. E outros disserom que o no caldo era melhor. E estes que assi fizerom estes departimentos cada hũu delles deu suas razões por sua parte ${ }^{42}$

A esta aclaración sigue una exposición detallada de las razones -fisiológicas, teológicas, empíricas- que justificaban cada una de las preferencias en relación con la alimentación de los canes; ello nos permite suponer que también la salud y la enfermedad de los animales originaban debates científicos, por más que apenas hayan quedado registrados en los tratados que nos han llegado.

Al igual que en el caso de aves y perros, los tratados de albeitería también especificaron el tipo de alimento que debía darse a las caballerías (ce-

${ }^{39}$ Sobre la alimentación en los regimina sanitatis, véase P. Gil-Sotres, Regimen sanitatis, pp. 645-733.

${ }^{40}$ Libre de animals de caçar, ff. 65r, 80v.

${ }^{41}$ Muhammad b. 'Abd Allāh, Libro de los animales que cazan, pp. 222-223.

${ }^{42}$ J.M. Abalo, Livro da Montaria, p.110. 
bada, salvado, algarrobas, hierba, etc.), la cantidad y en qué momento del día según la época del año. Y, al igual que lo que se observaba en otros animales y en las personas, la alimentación de las caballerías debía adecuarse a la edad del equino. Algunos tratados de albeitería ordenaron también el régimen de la bebida de caballos o mulas ${ }^{43}$.

La higiene del sueño ${ }^{44}$, la cuarta res non natural, es una de las que, a juzgar por la información contenida en los tratados, menos atención recibieron por parte de los cuidadores de los animales en la Edad Media; sin embargo, ello no significa que las referencias a la misma estén completamente ausentes en las obras medievales ${ }^{45}$. En el Libro de la caza de las aves se considera dormir ayuno una de las causas de enfermedad de los halcones, por lo qual deve todo caçador guardar que el su falcón sienpre duerma con alguna cosa en el papo o vianda o plumas $^{46}$. Por otra parte, en el De cane, de Alberto Magno, además de establecer un régimen para el sueño de los perros expone la justificación del mismo:

Regimen auten sanitatis canum est quod non permittantur multum dormire, quia cum caloris magni sit animal, quando dormit multum calor qui est circa locum nutrimenti intensus, attrahit malos humores ad stomachum et inficitur canis et infirmatur. Permittatur ergo dormire paululum post cibum et tantum quod cibus digeratur ${ }^{47}$.

\footnotetext{
${ }^{43}$ Pueden encontrarse estos aspectos del régimen de las caballerías en L. Faraudo (ed.), El texto primitivo inédito, pp. 9-10, y J. Gili (ed.), Lo cavall, pp. 43-44.

${ }^{44}$ Sobre la higiene del sueño en los regimina sanitatis, véase P. Gil-Sotres, Regimen sanitatis, pp. 735-752.

${ }_{45}$ Durante las primeras etapas del adiestramiento de las aves de caza, para lograr su amansamiento, se las privaba del sueño o se les limitaba en gran medida, algo que aparece perfectamente descrito en muchos tratados de cetrería medievales; posteriormente, una vez adiestradas, este control del sueño podía recomendarse en determinadas ocasiones o circunstancias. Sin embargo, no hemos considerado aquí estas referencias explícitas al régimen del sueño de las aves por estar orientadas al adiestramiento y al manejo de las mismas, más que a la conservación de su salud. Sin embargo, resulta necesario aclarar que, tanto en el caso del sueño, como en el de la alimentación de las aves -la cantidad y calidad de alimento constituía uno de los elementos básicos del adiestramiento y manejo de las mismas- sería necesario un estudio más detallado para discernir entre las prescripciones relacionadas con la salud y las relacionadas con el adiestramiento o la caza. El recurso al hambre y al cansancio de las aves, para el caso de los tratados latinos, ha sido puesto de manifiesto en B. Van den Abeele, La fauconnerie, pp. 125-126. Una descripción detallada de este aspecto del adiestramiento de las aves puede encontrarse en el tratado de cetrería del canciller Pero López de Ayala, en M. Delgado Montoto, Edición crítica del 'Libro de la caza de las aves', pp. 160-161.

${ }^{46}$ Ibidem, Edición crítica, pp. 375-376.

${ }^{47}$ J. Loncke, La Practica canum, p. 104.
} 
La función fisiológica que se atribuía a la evacuación ${ }^{48}$, la quinta res non natural, era la de eliminar los residuos o superfluidades de las tres digestiones que tenían lugar en el organismo, además del esperma y los humores. En el ámbito de la medicina de los animales, el cuidado de las aves de caza es el que más importancia parece haber dado a esta res non natural. Para que el "agua" no se acumulara en la cabeza de los halcones y produjera enfermedades, Pero López de Ayala recomendaba sienpre en la mañana e en la noche dar a tu falcón a tirar en roederos que aya nervios e plumas ca esto le faze sacudir el agua de la cabeça que se nunca faga vedriad ${ }^{49}$. En realidad, esta acumulación de superfluidades o humores en la cabeza también se consideraba causa de enfermedad de los caballos y, cuando esto sucedía, se prescribían remedios muy similares a los aplicados a las aves para evacuar estos humores de la cabeza ${ }^{50}$. También el estómago de los halcones debía ser limpiado diariamente de las humedades y limos que en él se producían y para ello se ordenaba que por la noche se hiciera ingerir a las aves su plumada (consistente en un puñadito de plumas, un trozo de algodón o de tejido) para que por la mañana, al regurgitarla, expulsaran con ella las mencionadas materias ${ }^{51}$. Además, el examen atento de esta plumada, al igual que el de las superfluidades en medicina humana, permitía conocer el estado de salud del ave. Por esa razón, en los tratados de cetrería se reiteraba la necesidad de mantener limpio el suelo debajo del posadero de las aves, para poder examinar las heces y la plumada de cada noche ${ }^{52}$.

${ }^{48}$ La evacuación en los regimina sanitatis puede verse en P. Gil-Sotres, Regimen sanitatis, pp. 753-801.

${ }^{49}$ M. Delgado, Edición crítica, p. 202. "Tirar en roederos" consistía en estirar repetida y violentamente el ave para arrancar con el pico pequeñísimos trozos de carne que se hallaban fuertemente adheridos a nervios y huesos de un miembro de animal sujetado por el halconero con el puño enguantado. Este movimiento violento de la cabeza del ave al intentar arrancar los trocitos de carne le hacía sacudir los humores y expulsarlos por las narinas o fosas nasales.

${ }^{50}$ Resultan muy interesantes las semejanzas en el régimen de aves y caballerías, así como en las curas respectivas. En un tratado de albeitería también se proponía, al igual que en el caso de las aves, una evacuación mecánica de humores por las fosas nasales: "que menje o pastur a vegades en loch on age erbes poques, car aytant com enclina lo cap envés terra gran pertida de les humors se decorren per les nerylls" (J. Gili (ed.), Lo cavall, p. 53). Cuando este remedio ya no era eficaz y debían evacuarse humores fríos de la cabeza de los caballos o de los halcones, tanto albéitares como cazadores recurrían a un procedimiento muy similar, consistente en calentar la cabeza colocando en ella un saco de tela con granos de trigo o de mijo muy calientes; para el caso de los caballos, véase J. Gil, Lo cavall, p. 66, y para el caso de las aves, véase M. Delgado, Edición crítica, pp. 231-233.

${ }^{51}$ Todos los tratados de cetrería estudiados destacan la importancia de las plumadas de las aves y de su adecuado régimen, pero donde mejor se expone la función de dicha plumada y el procedimiento para darla al ave es en una obra algo posterior, del siglo XVI (J. Vallés, Libro de acetrería, vol I, pp. 217-218).

52 "Otrosí la casa sea sin fumo e sin sereno e sin polvo e que non esté en ella cal ca los çiega e tenga el suelo deyuso de la alcándara linpio porque veas la plumada quando la fiziere, otrosí las tolleduras" (M. Delgado, Edición crítica, p. 175). 
También los albéitares reconocieron la importancia de la adecuada evacuación y describieron un dolor que s'engendra per sobre de reteniment d'orina en la vexyga y por eso recomendaban que deu om procurar que orinar al cavayll no sia contrast com va per lonch camí, car molt tarda orinar li donaria e li portaria ocasió de gran $\mathrm{mal}^{53}$.

Quizá podría pensarse que las emociones o el estado de ánimo, la última res non natural, estaría ausente de los tratados de albeitería o de caza. Sin embargo, las breves pero frecuentes referencias que aparecen en dichos tratados no hacen sino confirmar la importancia que en la baja Edad Media se daba a las emociones, atribuyéndoles una relación con la salud de los animales similar a la existente en las personas ${ }^{54}$. $\mathrm{Al}$ analizar este aspecto del cuidado de los animales no puede ocultarse la dificultad que supone distinguir cuándo una acción del cuidador que provocaba placer o alegría al animal estaba orientada a conservar la salud del mismo y cuándo formaba parte de las técnicas de adiestramiento que exigía el manejo de cada tipo de bestia ${ }^{55}$. En la obra de albeitería de Manuel Díez se explica cómo se debe cuidar el caballo en tiempo de paz, para que quien le toviere por su deporte o por estado, le sepa dar pienso para ser gruesso y muy alegre, y ende se pone la forma como le tenga mejor ${ }^{56}$. Para los perros de caza se aconsejaba que si estidieren muchos días que non salgan a caça, sáquenlos de dos en dos a ribera, ca con esto se alegrarán e serán ledos e serles á segundo si los sacaren a caça $a^{57}$. Muchos son los pasajes en los tratados de cetrería en los que se hace referencia a la alegría o placer que se debía hacer a las aves de caza. Pero López de Ayala recomendaba que después que venieres de fazer bolar tu falcón e ovieres çevado ponlo en una cámara en su alcándara e apartado porque piense de sí e tome plazer $^{58}$. Una de las referencias más claras de la importancia de las emociones para la salud de las aves de caza se encuentra en la recomendación de colocar en la cámara donde se aloja al halcón, çespedes verdes como en manera de prado que tome plazer con la verdura ${ }^{59}$. No obstante, la relación más explícita entre la salud del ave y la alegría se encuentra en una receta de una obra de cetrería relacionada con la tradición latina, el Libro de los azores, en la que, para curar al gavilán de una enfermedad, se prescribe que

${ }^{53}$ J. Gili (ed.), Lo cavall, pp. 46 y 58. También en G. Sachs, El libro de los caballos, p. 87, hay indicaciones relacionadas con la micción de los caballos.

${ }^{54}$ Sobre la relación entre las emociones y la salud, a partir de los regimina sanitatis, véase P. Gil-Sotres, Regimen sanitatis, pp. 803-827.

${ }^{55}$ Se trata de una dificultad análoga a la que se presenta al estudiar el régimen del sueño y la alimentación de los animales. Véase la nota 45.

${ }^{56}$ O. González, Libro de albeytería, p. 60.

${ }^{57}$ Muhammad b. 'Abd Allāh, Libro de los animales que cazan, p. 224.

${ }^{58}$ M. Delgado, Edición crítica, p. 202.

${ }^{59}$ Ibidem, p. 409. 
tomen palominos pequennos et échengelos delante, et sea el gavilán ssuelto, que l' prinda él con ssu mano et que beva la ssangre dél, et por el gozo que avrá de la prissión que 'l prende sserá sano $^{60}$.

\subsection{Enfermedades de los animales y su cura}

La fisiología del galenismo se basaba en una serie de conceptos que se agruparon formando lo que los médicos medievales denominaban res naturales: elementa, complexiones, humores, membra, virtutes, operationes, spiritus $^{61}$. Sin embargo, los cuatro humores -sangre, flema, bilis amarilla y bilis negra-, junto con el concepto de cualidad (articulado en un esquema de dos pares opuestos: frío-caliente y seco-húmedo) fueron quizá las herramientas conceptuales más ampliamente utilizadas por los médicos para explicar las enfermedades humanas y justificar los remedios. La salud del ser humano dependía, entre otros factores, del adecuado equilibrio de las cualidades -lo que se conocía con el término complexión- y las desviaciones de esta complexión equilibrada o temperada, es decir, las complexiones caliente, fría, seca, húmeda (o combinaciones de éstas), estaban asociadas a la enfermedad ${ }^{62}$.

$\mathrm{Si}$ en los tratados latinos sobre la cura de las aves, estas referencias a los humores y a las cualidades $-\mathrm{y}$, en general, a cualquier concepto o explicación teóricos- son más bien escasas ${ }^{63}$, los tratados posteriores que se compusieron en las lenguas vernáculas o se tradujeron del árabe fueron incorporando, al igual que los tratados de hipiatría, un número cada vez mayor de explicaciones teóricas, recurriendo, especialmente, a los conceptos galénicos de humor y cualidad para explicar las enfermedades que padecían y para aplicar el tratamiento adecuado. Para ello, una premisa fundamental era conocer

${ }^{60}$ J.M. Fradejas (ed.), Antiguos tratados, p. 94.

${ }^{61}$ M.R. McVaugh, (ed.), Tractatus de intentione medicorum, p. 30.

${ }^{62}$ L. García Ballester, La búsqueda de la salud, pp. 130-136.

${ }^{63}$ B. Van den Abeele, La fauconnerie, pp. 211-213. Una de las referencias más claras a la teoría médica en las obras latinas de cetrería es la clasificación de los halcones que ofrece el tratado Dancus rex; en esta obra se determina la complexión de los halcones por el color de su plumaje -negro, blanco o rojo-, declarando así la existencia de aves melancólicas, flemáticas y sanguíneas respectivamente, que debían ser alimentadas o tratadas mediante alimentos o medicamentos que tuvieran las cualidades contrarias a las del humor predominante en cada uno de estos tipos de halcones (G. Tilander, Dancus Rex, pp. 86-88). Sin embargo, en las traducciones vernáculas hispánicas estas explicaciones teóricas solo se conservaron en la versión catalana (J.M. Fradejas, M. Garcia, B. Van den Abeele, Tratados de cetrería catalanes, pp. 70-72), se redujeron drásticamente en la versión castellana (J.M. Fradejas (ed.), Antiguos tratados, p. 68) y desaparecieron por completo en la versión portuguesa conservada (G. Tilander, Uma tradução portuguesa desconhecida, pp. 443-447). 
la complexión propia, o en estado de salud, de las bestias que había que cuidar y esto se hizo explícito en algunas obras de caza. En general, se consideraba que las aves de cetrería eran de complexión caliente y seca, aunque dicha complexión, al igual que en el caso de las personas, podía variar de unas aves a otras y ser diferente también entre machos y hembras ${ }^{64}$. Del mismo modo, diferentes obras medievales atribuían a los perros una complexión caliente y seca, lo que permitía justificar cuál debía ser la mejor alimentación para ellos. Alberto Magno, en De cane, explica:

Scias autem quod sicut dicit Galienus in primo libro de Complexione, canis calidus est vivus, mortuus autem non. Calidus autem est respectu hominis et frigidus respectu leonis: et similiter siccus est respectu hominis, humidus autem respecto formicae et apis: et ideo si cibi naturaliter sicci et stiptici dantur canibus, constipantur et frequenter pereunt ${ }^{65}$.

Sin embargo, pese a coincidir en que os caães todos de sua natureza som quentes e secos, en el Livro da montaria se recogieron diferentes opiniones sobre cuál era el mejor alimento para los perros, basándose en la complexión de los canes y las cualidades de los diferentes alimentos. Una de ellas explicaba que

porque os caães som de sua compleixom seca, que comendo a carne que he humeda que deuia de correger en aquella secura,

mientras que otra opinión argumentaba que

quando comessem carne, porque era cousa muy fraca, non poderiam sofrer a gram quentura que os caães ham e era de força que se tornasse todo en fumos, os quaes non poderiam muyto criar nem correger a sua compleixom ${ }^{66}$.

\footnotetext{
${ }^{64}$ La complexión de las aves de caza y las consecuencias para la salud que se derivaban de ello se explicaba con todo detalle en un tratado árabe medieval, donde se aclaraba que "tanto el azor como el resto de las aves de caza han sido creados también de las cuatro naturalezas, pero en ellos predomina el calor y la sequedad, que es la cualidad del fuego; su naturaleza originaria es caliente y seca y su complexión originaria, en estado de salud, es caliente y seca como la bilis amarilla". Entre las enfermedades internas está "el exceso de humores, que son los que constituyen la causa de las enfermedades de las aves de presa y son tres: sangre, flema y viento. La enfermedad de sangre es caliente y húmeda, la de flema es fría y húmeda y el viento, con la cualidad de la bilis negra, es frío y seco. Las aves de presa solo padecen enfermedades de bilis amarilla raramente, porque su complexión originaria natural es caliente y seca, que es la cualidad de la bilis amarilla y cuando domina en ellas dicho humor, sanan y se equilibra su naturaleza" (al-Baladī, Kitāb al-kāfì , pp. 201 y 207). Sobre la diferente complexión de machos y hembras véase, por ejemplo, Libre de animals de caçar, ff. 4v-5r.

${ }^{65}$ J. Loncke, $L a$ Practica canum, p. 108.

${ }^{66}$ J.M. Abalo, Livro da Montaria, pp. 108-112.
} 
La importancia de estos testimonios estriba en que revelan la existencia de debates en torno a la alimentación y, en general, a la higiene de los animales y que en dicho debate se empleaban conceptos y argumentos propios del galenismo.

A diferencia de aves de caza y perros, a los caballos se les atribuía una complexión caliente y húmeda, lo que tenía importantes consecuencias para su salud y condicionaba el régimen adecuado para ellos ${ }^{67}$.

Además de la complexión, otro aspecto importante que el médico debía tener en cuenta a la hora de tratar a sus pacientes eran las costumbres y el modo de vida de éstos ${ }^{68}$. Los cambios bruscos, al igual que para las personas, también se consideraban perjudiciales para la salud de los animales, incluso aunque estos cambios mejoraran la alimentación o algún otro de los elementos de la higiene medieval. Por esta razón advertía Pero López de Ayala de las precauciones que había que tener cuando se compraban halcones que habían sido mantenidos mucho tiempo mediante una mala alimentación, pues

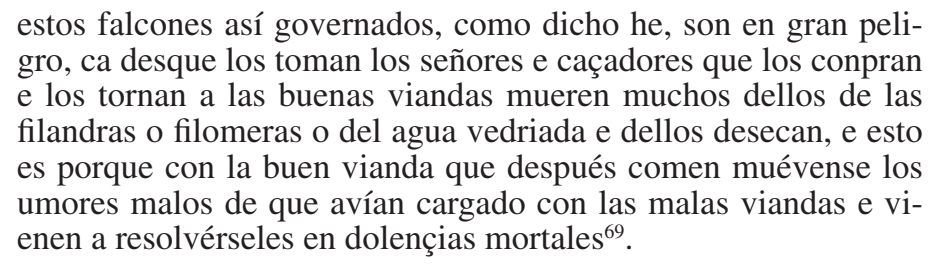

Para los médicos medievales, la corrupción de humores, el exceso de alguno de ellos o la acumulación anormal en algún lugar del cuerpo, eran la causa de muchas enfermedades y es precisamente esta explicación de la enfermedad la que empleaba el canciller en su advertencia. Esta interpretación fisiológica de la enfermedad estaba en la base de las prescripciones higiénicas tendentes a facilitar la evacuación de las superfluidades naturales y a evitar que se produjeran humores corruptos o en exceso, del mismo modo que justificaba muchos de los remedios que se aplicaban una vez que la enfermedad se había originado ${ }^{70}$. Es muy ilustrativa la explicación fisiológica que se ofrece en El libro de los caballos para cierta enfermedad, por cuanto describe gran parte del proceso de digestión, empleando los términos y conceptos de la doctrina del galenismo:

\footnotetext{
${ }^{67}$ G. Sachs, El libro de los caballos, pp. 72-73.

${ }^{68}$ Véase, por ejemplo, P. Gil-Sotres, Regimen sanitatis, p. 505, y, en la misma obra, los diferentes capítulos sobre cada una de las res non naturales en los regimina sanitatis.

${ }^{69}$ M. Delgado, Edición crítica, pp. 95-96.

${ }^{70}$ P. Gil-Sotres, Tractatus de consideracionibus operis medicine, p. 9.
} 
Faze se mal al cauallo en la boca por razón del comer que es podrido e ques engendra de sangre flematica e mala del comer por que es calient much e no es bien cocha; ca el beço recibe el meior sugo del comer por que es muy calient e tornallo en sangre e esparzelo por las uenas, e parte se por todos los miembros del cuerpo, por que se conforten e se crien por calentura e por regamiento de la sangre. E dize que si la sangre non conuiene a la natura, si la [su]perfluidat della no es menguada o non se desfaze por moui[mi]entos o por usos por los que deuen seer temprada o minguada o seer fuera echada por sudor, la natura esfuerça se quanto puede echar fuera las superfluidades en alguna parte del cuerpo. Quando la la superfluidat finca en algun logar dela humor, tal enfermedat prende nombre del miembro en que cae ${ }^{71}$.

Los tratados de albeitería y de caza bajomedievales basaban sus remedios en algunos principios básicos que el galenismo había establecido para la medicina humana. Proporcionar un régimen adecuado para conservar la salud de los animales y evitar que aparecieran enfermedades era un principio recomendado por albéitares antes de describir las enfermedades y su tratamiento:

Primerament direm en qual manera sanitat sia conservada, e aprés perduda, e qual manera sia recobrada. Feelment expondrem e millor, ço és ab diligencia d'estudi, conservar e guardar sanitat e que donar remey a quells qui son malalts ${ }^{72}$.

En caso de aparición de enfermedad, el galenismo recomendaba aplicar en primer lugar los remedios menos contrarios al organismo. Es decir, se debía intentar curar mediante una dieta adecuada y solo si se fracasaba con ello se debían administrar medicamentos; el recurso a la cirugía debía ser la última instancia. Juan Manuel, en su Libro de la caza no hace sino seguir dicho principio al recomendar

que l' den a mesar et tirar [al falcón], et si por esto guaresçiere, non le fagan otra melezina. Ca todas las melezinas son contrarias de los cuerpos de los falcones et non gelas deven dar sinon quando non se puede escusar en ninguna manera ${ }^{73}$.

Para evacuar humores corruptos o sobreabundantes se podían utilizar purgantes, sustancias prescritas por cazadores y albéitares para limpiar el

\footnotetext{
${ }^{71}$ G. Sachs, El libro de los caballos, p. 74.

${ }^{72}$ J. Gili (ed.), Lo cavall, p. 42.

${ }^{73}$ J.M. Fradejas (ed.), Don Juan Manuel, p. 181.
} 
cuerpo de los animales o algún miembro particular de los mismos. Estas sustancias, al igual que sucedía en medicina humana, se podían administrar tanto para curar determinadas enfermedades como para prevenirlas, especialmente en determinadas épocas del año. Pero López de Ayala recomendaba purgar a las aves de caza, entre otras razones, porque de no hacerlo les recresçen otras dolençias mayores. En cualquier caso, el purgante solo se debía suministrar si los falcones están rezios $\mathrm{y}$, al igual que se hacía en medicina humana, catando el cuerpo e la conplisión del falcón ca uno ha menester más granos que otro ${ }^{74}$.

Médicos, albéitares, cazadores y halconeros compartían la convicción de que las enfermedades evolucionaban en el organismo, siendo su cura más sencilla cuando ésta empezaba a desarrollarse, llegando a hacerse incurable, en algunos casos, cuando la enfermedad se afirmaba o se hacía vieja ${ }^{75}$. Además, la evolución de algunas enfermedades las llevaba a transformarse en otras muy distintas. El Libro de la caza de las aves explica cómo la enfermedad conocida con el nombre de agua vedriada se podía transformar en pérdida de la vista:

acaesçe por tal figura que esta agua vedriada atapa los caños, así de las ventanas e de ojos e narizes e esta agua non ha por do salir e tórnase a la cabeça donde se engendró e por fuerça del atapamiento de los caños pónese sobre el meollo e faz perder la vista al falcón ${ }^{76}$.

Por otra parte, el Libro de la caza explicaba cómo, tras aplicar los tratamientos prescritos para el agua vidriada,

non se puede escusar una de dos cosas: o madura[rá]l' el agua et començar[á] a salir por las ventanas, o será tan espessa que non podrá salir et averse á podresçer et tornarse á en güérmezes ${ }^{77}$.

El cauterio y la sangría proporcionaban a médicos, cazadores y albéitares procedimientos quirúrgicos adicionales para evacuar humores corruptos o excesivamente abundantes. Para curar la malaltia de fredor com fa inflar lo cap del cavall se indicaba:

${ }^{74}$ M. Delgado, Edición crítica, pp. 242-243.

${ }^{75}$ Sobre la evolución de las enfermedades, véase L. García Ballester, La búsqueda de la salud, pp. 133-134. Bernardo Gordonio, para algunas enfermedades de los humanos distingue varias etapas: comienço, pujamiento, estado y declinación (J. Cull, B. Dutton (eds.), Un manual básico, p. 130), mientras que en un tratado de albeitería se advierte que "En lo començament de la malaltia hi pot hom mills remey donar" (J. Gili (ed.), Lo cavall, p. 49).

${ }^{76}$ M. Delgado, Edición crítica, pp. 235-236.

${ }^{77}$ J.M. Fradejas (ed.), Don Juan Manuel, p. 182. 
coga-li hom aquelles glànoles que hom apella nives qui són entre-ll cap y el coyll del cavayl; e cové que ho faça ab ferre calt redon e sien cuytes ben e soptilment per tal que les humors qui per la fredor son escomogudes vaporen de fora ${ }^{78}$.

Remedios similares se prescribían para curar enfermedades de aves y perros, indicando con precisión el lugar y el modo en que debían aplicarse dichos cauterios ${ }^{79}$.

La flebotomía, que tanta aplicación tuvo en la medicina humana medieval, fue igualmente empleada con frecuencia por los albéitares para evacuar la sangre excesiva y otros humores corruptos en las caballerías, indicando el lugar exacto en que se debía sangrar y la cantidad de sangre que se debía extraer ${ }^{80}$. Estas sangrías, al igual que para las personas, se recomendaban también para los caballos varias veces al año de forma preventiva ${ }^{81}$. Aunque menos frecuentes, no faltan en las obras que se ocuparon del cuidado de los perros indicaciones para sangrarlos con el fin de curarlos de distintas enfermedades ${ }^{82}$. En el caso de las aves de caza, la sangría propiamente dicha (abriendo la vena) parece que fue menos practicada ${ }^{83}$, aunque la extracción de sangre fue igualmente recomendada en determinadas ocasiones:

quando vieres que al tu falcón finchan los pies e non lo ha de las malas o duras pihuelas fazle cortar las uñas todas a raíz del maslo e fazlo con buen tiento ca cunple asaz que salga sangre de todas e salga mucha sangre ${ }^{84}$.

${ }^{78}$ J. Gili (ed.), Lo cavall, p. 66

${ }^{79}$ M. Delgado, Edición crítica, pp. 230-231; Muhammad b. 'Abd Allāh, Libro de los animales que cazan, p. 233.

80 "si lo cauall te los senyals damunt dits deueulo sagnar de la vena del coll segons la força e la edat del cauall e si es fort e ha sinch anys deueu li traure tres liures de sanch" (M. Dieç, Tractat, f. 47r).

81 "E si vols conservar lo cavayll de contraris, tres vegades l'ayn almenys lo sagnaràs" (J. Gili (ed.), Lo cavall, p. 106).

${ }^{82}$ Muḥammad b. 'Abd Allāh, Libro de los animales que cazan, p. 233; J. Loncke, La Practica canum, p. 105.

${ }^{83}$ Sobre la sangría en los tratados latinos de cetrería, véase B. Van den Abeele, La fauconnerie, pp. 246-247, donde se pone de manifiesto que se trata de un procedimiento muy poco prescrito en dichos tratados. Sin embargo, pese a no ser frecuente, la sangría tampoco está completamente ausente de los tratados de cetrería en lenguas vernáculas. Si en una de las obras castellanas de la tradición latina se prescribe, de forma muy escueta, la sangría para una enfermedad de las aves (J.M. Fradejas (ed.), Antiguos tratados, p. 42), en un tratado italiano posterior de medicina de las aves se dan instrucciones muy precisas sobre el modo de realizar esta operación (M. Mercader, Pratica de citreria breve, f. 35r). Sin duda, la fragilidad de las aves debió impedir la generalización de esta técnica preventiva y terapéutica en estos animales.

${ }^{84}$ M. Delgado, Edición crítica, pp. 330-331. 
El cuerpo humano, cada miembro del mismo, cada alimento o medicina tenía su complexión y, del mismo modo, también a las enfermedades les asignaba la medicina galénica unas cualidades dentro del esquema fríocaliente, seco-húmedo. Este hecho estaba en la base del principio terapéutico contraria contrariis curantur, según el cuál las medicinas debían tener cualidades contrarias a las cualidades de la enfermedad que se pretendía curar. Este principio, aunque no aparece explícito en las obras de albeitería y caza, subyacía en algunos de los remedios de dichos tratados ${ }^{85}$.

Sin embargo, las complexiones o cualidades -frío, caliente, húmedo y seco- no fueron las únicas propiedades curativas reconocidas de las medicinas. Desde antiguo, a los simples se les atribuyeron otras propiedades específicas, conocidas empíricamente, y que fueron integradas en la doctrina del galenismo como propiedades o potencias secundarias y terciarias, asumiendo que se deducían de las cualidades fundamentales o primarias. Así, las potencias secundarias eran aquellas que producían un efecto concreto sobre todo el cuerpo, mientras que las potencias terciarias serían las que producían un efecto sobre un miembro en particular ${ }^{86}$. Estas potencias secundarias, más familiares para los médicos, parecen también conocidas por los responsables de la salud de los animales cuando aconsejan: faça-li om molificatiu..., mortiffiquen ab pólvora de afodilox o ab altra pólvora qui era bona, (...) cur-la om d'aquí avant ab coses qui la consolden... o y val pólvora de fundillorum o altres pólvores corroxives ${ }^{87}$. De este modo, más que las cualidades primarias de las medicinas, el recurso a sus propiedades secundarias -resolutivas, madurativas, mundificativas, consolidativas, corrosivas, etc.- parece a menudo estar en la base de muchas prescripciones. Una prueba muy ilustrativa de la conciencia que debían tener los cazadores de la importancia de cualidades y propiedades de las medicinas y su forma de actuar en el organismo es la sección incluida en uno de las tratados de cetrería, en la que se detallan las cualidades y grados de un gran número de sustancias, así como sus propiedades específicas ${ }^{88}$.

Otro aspecto destacable de la medicina de los animales es la atención prestada por los cazadores a las superfluidades de las aves como forma de co-

\footnotetext{
${ }^{85}$ Por ejemplo, en un tratado de albeitería se explica que "simorra és malaltia qui devalla del cap del cavall antigament refredat" y para dicha enfermedad se aconseja "faça-li hom e li don menjars calts, e tinguen lo cap cubert ab drap de lana estant en loch calt" (J. Gili (ed.), Lo cavall, p. 53).

${ }^{86}$ H.M. Paavilainen, Medieval Pharmacotherapy, pp. 53-55; M.R. McVaugh, (ed.), Aphorismi de gradibus, pp. 3-11.

${ }^{87}$ J. Gili (ed.), Lo cavall, pp. 81, 92, 93 y 96.

${ }^{88}$ A.M. Rico (ed.), 'Libro de las aves que cazan', pp. 597-621. En realidad no está claro si esta información es obra del autor del tratado o del de las glosas; véase, J.M. Fradejas, Literatura cetrera, p. 37.
} 
nocer el estado de salud de las mismas y diagnosticar las enfermedades, algo similar a lo que sucedía en medicina humana. En particular, resulta muy significativo el paralelismo existente entre la cuidadosa observación de la orina humana para seguir los procesos fisiológicos del cuerpo humano y diagnosticar enfermedades y la atención similar prestada a las tulliduras o heces de las aves con idéntica finalidad ${ }^{89}$. Ya en un tratado árabe de cetrería del siglo X se estableció explícitamente esta relación:

Sache que les émeuts sont, pour l'oiseau de vol, ce que l'urine est pour l'homme. L'autoursier éclairé diagnostique l'affection de l'oiseau de vol d'après ses émeuts, comme le médecin averti le fait de la maladie de l'homme d'après l'urinal. Et même, les émeuts sont plus dignes de confiance et plus sûrs que l'urine humaine, car l'oiseau de vol n'ingurgite que son pât qui n'est que chair vive; celle-ci lui convient-elle, on le voit dans ses émeuts et, si elle ne lui réussit pas, ses émeuts ne manquent pas de vous le dire ${ }^{90}$.

El valor atribuido por los cazadores a las tulliduras de las aves queda claro por la recomendación explícita que hicieron los autores de los tratados de cetrería de mantener limpio el suelo debajo de los posaderos de las aves, para poder observar adecuadamente dichas tulliduras y plumadas. Además, en ocasiones, en dichos tratados, la descripción de las heces cuenta entre las señales de la enfermedad. Pero López de Ayala explicaba que para reconocer el

fenchimiento del buche del falcón ... lo verás toller las tolleduras gruessas e allí onde ha de venir la materia negra entre la blanca tiene unas cagadillas que paresçen de mures ${ }^{91}$.

Otras obras dedicaron una amplia sección o capítulo específico al diagnóstico, por medio de las heces, de un gran número de enfermedades ${ }^{92}$.

Aunque en menor medida, también en los tratados de albeitería se encuentran referencias a las características de superfluidades -heces y orina- de los caballos para reconocer determinadas enfermedades o estados de los mismos ${ }^{93}$.

Para concluir esta revisión de los elementos del galenismo y de la medicina humana presentes en las obras dedicadas al cuidado de los animales, podemos constatar la semejanza formal en la exposición de los conocimientos

${ }^{89}$ L. García Ballester, La búsqueda de la salud, pp. 133-134.

${ }^{90}$ F. Viré (trad.), Le traité de l'art de la volerie, p. 72.

${ }^{91}$ M. Delgado, Edición crítica, pp. 283-284.

${ }_{92}$ Muḥammad b. 'Abd Allāh, Libro de los animales que cazan, pp. 103-105.

93 "Quando la sangre cresce much al cauallo estos so[n] los signos por que lo puede omne conoçer. El primero es que se ama mucho rascar. El segundo, fiede much el estiercol que faze. El tercero, la orina faz uermeia e espesa." (G. Sachs, El libro de los caballos, pp. 71-72). 
médicos. El orden de exposición de las enfermedades, a capite ad calcem, habitual en los tratados de medicina humana es, a menudo, el seguido en los tratados de caza o albeitería. En algunos casos, este esquema de exposición es anunciado en la obra, como en el Libro de la caza, donde se aclara:

Et las enfermedades que an en los cuerpos e que agora usan melezinar fízolas escrivir don Johan fablando primeramente en las de la cabesça et después en el papo et en el cuello, et así irá desçendiendo fasta las uñas et a las péñolas ${ }^{94}$.

En el Libro de los animales que cazan, tanto en la parte dedicada a las aves, como en la dedicada a las enfermedades de los perros y otros mamíferos, esta ordenación habitual a capite ad calcem se sigue después de una primera división entre enfermedades que an de dentro y enfermedades que parecen de fuer ${ }^{95}$. En concreto, en el tratado dedicado a los perros, se aclara que en primer lugar

queremos dezir en este capítolo los melezinamientos de las enfermedades de los ojos porque son los primeros miembros e son en el más alto logar del cuerpo, e después seguiremos adelante en dezir los melezinamientos de todos los otros miembros ordenadamientre fasta que sean acabados ${ }^{96}$.

Además del orden expositivo de las enfermedades de los animales, otros aspectos formales también presentan semejanzas con los tratados de medicina humana. Habitualmente cada enfermedad suele presentarse en un capítulo, el cuál contiene una descripción más o menos detallada de la enfermedad, en la que se explican las causas de la misma y las señales para conocerla: quando el falcón á lonbrizes, la señal es que se le descoloran las manos et la çera del pico, et el falcón mésase en aquel logar do lo siente ${ }^{97}$. En ocasiones el autor proporciona un breve pronóstico, aclarando si se trata de una enfermedad de fácil o difícil curación: Estas filandras o filomeras de que agora fabla este capítulo es una dolençia de que pocos falcones guaresçen ${ }^{98}$ con esta melezina nunca vio falcón a que los echassen que non guaresçiesse, salvo si los güérmezes eran llegados a las orejas: ca desque ý llegan, pocos o ningunos son los que ende escapan ${ }^{99}$, para terminar exponiendo el tratamien-

\footnotetext{
${ }^{94}$ J.M. Fradejas (ed.), Don Juan Manuel, p. 181.

${ }^{95}$ Muḥammad b. 'Abd Allāh, Libro de los animales que cazan, pp. 109-112 y 195-196 (aves y perros, respectivamente).

${ }^{96}$ Ibidem, p. 231.

${ }^{97}$ J.M. Fradejas (ed.), Don Juan Manuel, p. 168.

${ }^{98}$ M. Delgado, Edición crítica, p. 293.

${ }^{99}$ J.M. Fradejas (ed.), Don Juan Manuel, p. 183.
} 
to o cura. En esta última sección suelen presentarse diferentes tratamientos alternativos indicando, en ocasiones, aquél que debe seguirse cuando ningún otro ha dado resultado: Item si veyets que ab neguna de aquestes medeçines se milloraua lo oçell ne guaria fets li aquesta medeçina e guarra ${ }^{100}$. Las recetas con las instrucciones para la elaboración de los medicamentos suelen constituir la parte más importante del capítulo dedicado a cada enfermedad, donde la acumulación de dichas recetas reproduce una situación habitual en los tratados de medicina humana.

El carácter práctico de los escritos sobre cuidados de los animales podría ser una de las causas de la escasez o brevedad de argumentaciones teóricas en tratados de caza y albeitería, lo cuál no quiere decir que la práctica médica no tuviera una base o fundamentación teórica. Por otra parte, los cazadores y albéitares debían ser conscientes de la importancia y la dificultad de la teoría de la doctrina, pues en el Libro de la caza se declaraba

que sepan todos los que este libro leeyeren que el que bien sopiere la teórica del arte de la caça et la prática et usare por ella como deve en todas las cosas que son dichas et pertenesçen a la prática et en las que non son dichas que pertenesçen a la teórica, que usando en todo como deven, que non errarían en ninguna cosa... Et porque la teórica del arte de la caça es muy grave de se saber verdaderamente, dize don Johan que non se atrevió él a fablar en ella ninguna cosa, salvo ende quanto tañe, a lo que se allega la teórica, a lo que se agora usa en las enfermedades de los falcones ${ }^{101}$.

\section{LOS MISMOS REMEDIOS PARA LOS MISMOS MALES}

La escasez de argumentación racional en los tratados de medicina animal hace que la determinación de relaciones con la medicina humana deba recurrir a menudo a una interpretación galénica de numerosos pasajes de los textos sobre cuidados de los animales. Sin embargo, los remedios propuestos para determinadas enfermedades permiten una comparación directa y una evaluación del grado de correspondencia entre las curas prescritas para las personas y las curas para los animales, tanto en la materia medica empleada para la elaboración de medicamentos, como en las operaciones propias del cirujano. Para determinar en qué medida los remedios para los males de perros, aves y caballos correspondían a los prescritos para las personas hemos seleccionado dos enfermedades -más bien grupos de enfermedades- que padecían

${ }^{100}$ Libre de animals de caçar, f.49v.

${ }^{101}$ J.M. Fradejas (ed.), Don Juan Manuel, pp. 180-181. 
tanto humanos como bestias y hemos comparado los tratamientos recogidos en los manuales de albeitería y caza con los indicados en dos obras medievales de medicina general en castellano: el Lilio de medicina, de Bernardo Gordonio, y la obra anónima Tratado de patología ${ }^{102}$.

\subsection{Las enfermedades de los ojos y su cura}

No faltan, en los tratados de albeitería y de cetrería, así como en aquellos que contienen información sobre el cuidado de los perros, descripciones de diversas enfermedades de los ojos y el tratamiento para las mismas. El hecho de que las mismas enfermedades aparezcan en los tratados de patología y terapéutica humanas bajomedievales sugiere una relación entre la medicina humana y la animal en la baja Edad Media ${ }^{103}$. Pese a que en algunos casos tan solo se hace referencia a una imprecisa malaltia qui.s fa als cavalls en los ulls ${ }^{104} \mathrm{o}$ a un mal d'ulls [dels sparvers e falcons] ${ }^{105}$, en general, los mencionados tratados sobre el cuidado de los animales se refieren a unas cuantas enfermedades concretas: nube, uña, lagrimeo y heridas. Los autores y traductores de estas obras emplearon diferentes términos para referirse a estos males, aunque en muchos casos mencionaron explícitamente las sinonimias entre dichos términos (brancura que llaman пиие... ${ }^{106}$ ) y en otros casos indicaron que se trataba de formas o estados diferentes de la enfermedad o que una de ellas podía derivar de otra:

Devéis de entender que sobre la córnea acontecen passiones muchas que parecen que non ay diferencia entre ellas, salvo segund más e segund menos, ansí como son nuves e blancura e mancha e paño e tela, las quales vienen alguna vez por corrimiento de humores e algunas vezes por caída o ferida del ojo, e algunas vezes son reliquias de apostemas mal curadas ${ }^{107}$.

\footnotetext{
${ }^{102}$ Para una contextualización de dichas obras, véase la introducción de cada una de las ediciones: J. Cull, B. Dutton (eds.), Un manual básico, pp. I-XIX; M.T. Herrera, M.N. Sánchez (eds.), Tratado de patología, pp. 7-16.

${ }^{103}$ No es nuestra intención identificar, a partir de las informaciones de los tratados, las enfermedades oculares que padecían animales y humanos haciéndolas corresponder con enfermedades actuales. Precisamente por ello, tampoco pretendemos determinar si, según la nosología actual, las enfermedades que se atribuían a animales eran las mismas que las que padecían las personas. En realidad, nuestro interés se centra más bien en determinar en qué medida estas enfermedades eran consideradas, por médicos, albéitares y cazadores como un mismo mal que podían padecer tanto animales como humanos y, en consecuencia, recibían remedios similares.

${ }^{104}$ M. Dieç, Tractat, f. 31v.

${ }^{105}$ Rocabertí, Llibre de cetreria, f. $21 \mathrm{v}$.

${ }^{106}$ M.T. Herrera, M.N. Sánchez (eds.), Tratado de patología, p. 229.

${ }^{107}$ J. Cull, B. Dutton (eds.), Un manual básico, p. 137.
} 
$\mathrm{Al}$ margen de los problemas terminológicos, lo que claramente ponen de manifiesto los tratados de medicina animal al referirse a las enfermedades de los ojos es la idea, propia de la medicina humana medieval, de que las enfermedades evolucionan, pudiendo transformarse en otras enfermedades. Además, en algunos casos, distinguían entre enfermedades recientes y enfermedades viejas, lo que exigía tratamiento diferente, algo también propio de la medicina humana ${ }^{108}$.

Más allá de los aspectos nosológicos, la terapéutica nos muestra de forma clara la estrecha relación entre medicina humana y la medicina de los distintos grupos de animales. Y es que un estudio detallado de los remedios empleados para curar las enfermedades de los ojos permite poner de manifiesto la universalidad de muchas curas, tanto quirúrgicas como farmacológicas.

Además de una dieta adecuada, purgas, sangrías y cauterios constituían, a menudo, una primera intervención en la cura de las enfermedades de los ojos. En el Lilio de medicina, para la cura del paño se propone que

En el comienço fagan sangría de ambas a dos venas de la cabeça, e después, si fuere menester, de las venas que son en la frente e en las tímporas, e después de las venas que son en los dos ángulos de los ojos. E después sea purgado con gerapriga, e acostumbre dieta sotil e escuse todas las cosas fumosas ${ }^{109}$.

Lo que se buscaba con estas intervenciones era evacuar los humores corruptos o sobreabundantes causantes de la enfermedad. Recomendaciones similares encontramos en las obras sobre los cuidados de los animales. Según El libro de los caballos, para la nube de los ojos se debe

cortar le una uena que ua so el oio; trauersargela toda que non ay a periglo e non salle della si non poca sangre, e sangrar le en otra uena que ua cerca la sen e es mas gorda que esta e ua del trauiesso del oio ${ }^{110}$.

Juan de Sahagún, para el caso de la uña en los ojos de las aves, recomendaba

que quando les acaesçiere esta enfermedat de los ojos, que los purguen de los cuerpos con píldoras de rasis, aquellas que son falsas (hechas) de açíbar çicotrí e de mirra e açafrán ${ }^{111}$.

\footnotetext{
${ }^{108}$ Véanse las notas 75-77.

${ }^{109}$ J. Cull, B. Dutton (eds.), Un manual básico, p. 133.

${ }^{110}$ G. Sachs, El libro de los caballos, p. 26.

${ }^{111}$ A.M. Rico (ed.), 'Libro de las aves que cazan', p. 450. En el siglo XVI, Juan Vallés recoge, revisa y ordena gran parte de los conocimientos médicos relacionados con las aves transmitidos durante la Edad Media y en su obra recomienda otra purga: "Para que con más facilidad se
} 
La prescripción de Juan de Sahagún, pese a diferir en la técnica - purga en lugar de flebotomía-, puede interpretarse como un procedimiento equivalente, ya que con ambas operaciones lo que se buscaba era la evacuación del humor causante de la enfermedad. El recurso, en este caso, a la evacuación mediante un procedimiento menos agresivo estaría en consonancia con la baja frecuencia con que aparece la sangría como remedio en los tratados de cetrería, en significativo contraste con lo que se observa en los tratados de hipiatría o de medicina humana, donde se muestra como un procedimiento muy utilizado $^{112}$. La atención prestada a la dieta en el proceso curativo también queda bien patente en otro tratado de cetrería, donde se recomienda, cuando lo falcó o lo ocell te blancor o desfeta o tel en l'ull, darle a menjar de bon past calt e lexatiu mientras se sigue el tratamiento con los remedios prescritos ${ }^{113}$. Así pues, adaptar la dieta a las circunstancias y evacuar los humores con las distintas técnicas disponibles y adecuadas a cada caso era algo que, aunque expuesto en los tratados de albeitería y caza de manera menos extensa y detallada que en los de medicina humana, estaba en la base de la cura de las enfermedades oculares de los animales.

Para el mal denominado "uña" se recurría a la cirugía después de intentar la cura con medicamentos, según el principio de la medicina bajomedieval. Bernardo Gordonio aconsejaba:

E si no se curare con estas cosas, recorrámonos a las manos del cirujano, e abran los párpados, e saquen la uña con uncino, e descárnenla con un cabo de péndola sotil, e córtenla con tigeras. E en el cortar aya dos cautelas. La primera que toda se corte, que en otra manera luego se tornará ${ }^{114}$.

Intervenciones muy similares encontramos en los tratados de cetrería, como en el mencionado de Juan de Sahagún quien, para curar al halcón de la uña, explicaba:

Tomen una aguja e cósanle los paladares de los ojos con un filo en baxo e otra ençima, y dexen gelo allí de manera que non se salga, e esté el falcón derribado e enbuelto en un paño. E estos filos son por que pueda mejor abrir los ojos. E toma una aguja de alanbre, que tenga bien delgada la punta, e métela entre la uña e el ojo, aquella aguja, e arranca gela si podieres, y corta gela con un

pueda quitar la nube o paño del ojo purguen la ave con una píldora de las masticinas o de las de assajaret o de las de yera mezcladas con agárico" (J. Vallés, Libro de acetrería, p. 279).

${ }^{112}$ Sobre la sangría en las aves, véase la nota 83.

${ }^{113}$ Libre de animals de caçar, f. $48 \mathrm{v}$.

${ }^{114}$ J. Cull, B. Dutton (eds.), Un manual básico, p. 132. 
cañivete de péñola chiquito, e si non la podieres cortar, remuévela por que la melezina la pueda comer e gastar ${ }^{115}$

En la materia medica es donde se pone más claramente de manifiesto la estrecha relación que debió existir entre la medicina humana y animal en la baja Edad Media. Prácticamente todas las sustancias de origen vegetal, animal y mineral empleadas como remedio para curar las enfermedades oculares de estos animales, bien como medicinas simples, bien como ingredientes de compuestos, se encuentran entre las que se prescribían, para dichas enfermedades, en los tratados de medicina humana.

Resulta llamativo que, entre las sustancias de origen animal, las heces de lagarto, a menudo en combinación con otras sustancias y preparadas en forma de polvos, aparezcan como remedio para la nube en los ojos de los animales y de las personas. Manuel Díez recomendaba para los caballos que padecían enfermedades en los ojos, que prengau sal ben picada e mesclaulo ab fempta de luert e meteulin dintre los vlls ab un cano buffant ${ }^{116}$. En el Libre de animals de caçar, encontramos que pera guarir lo falcó o lo oçell que te blancor o desfeta o tel en l'ull hay que preparar unos polvos a partir de lo blanch de la femta del fardacho ${ }^{117}$, algo que también encontramos en otros tratados de cetrería $^{118}$. Por otra parte, Bernardo Gordonio, entre las recetas para curar la nuve en las personas, incluía la fórmula para la preparación de un colirio a base de múltiples ingredientes, apareciendo entre ellos el estiércol de lagarto verde ${ }^{119}$.

Resulta revelador el hecho de que, en algunos casos, no sólo coincidan las sustancias empleadas para curar los ojos de animales y personas, sino que exista una gran semejanza en el modo de preparación y aplicación del remedio. Para curar los ojos del caballo, Manuel Díez escribía:

Si los vlls del cavall lacrimejen feuli vn estrenyedor al front fet de un fust que a nom libano e de mastech tot picat en eguals parts e preneu blanc de hou ben debatut e meteu lo sobre una bena de drap de li que sia tan ample com lo dit e que baste a ligar lo cap tot entorn: e apres raeuli los polsos e lo front e ligauli aquella bena ab dits materials lo qual ha nom estrenyedor ${ }^{120}$.

115 A.M. Rico (ed.), 'Libro de las aves que cazan', p. 450. Pese a que Juan de Sahagún contó con el Libro de los animales que cazan entre sus fuentes, donde también se describe esta operación, su explicación es más detallada y próxima a la del Lilio de medicina.

${ }^{116}$ M. Dieç, Tractat, f. 32r.

${ }^{117}$ Libre de animals de caçar, f. 48v.

${ }^{118}$ En las glosas que Beltrán de la Cueva escribió para el libro de Juan de Sahagún se prescribe la "yenda de lagarto que tienen los boticarios" (A.M. Rico (ed.), 'Libro de las aves que cazan', p. 447).

${ }^{119}$ J. Cull, B Dutton (eds.), Un manual básico, p. 138.

${ }^{120}$ M. Dieç, Tractat, f. 32r. 
Por su parte, Bernardo Gordonio, para curar cierto tipo de obtalmía, recomendaba:

E d'estas con acacia e bol arménico e sangre de drago e claras de huevos fagan emplasto e a la frente e a las tímporas lo pongan (...). E si la causa fuere fría, apriétenlo con encienso e almástiga e mançanilla e corona de rey e rosas ${ }^{121}$.

Pese a que la receta para personas contiene más ingredientes y es más detallada que la receta para caballos, el hecho de que en ambos casos se trate de un emplasto, que se aplique en las mismas zonas -frente y sienes- y que los tres ingredientes de la receta para caballos -clara de huevo, incienso y almáciga-sean también ingredientes de la receta para personas, sugiere que podría subyacer una fórmula básica, válida tanto para humanos como para animales. Por otra parte, es de destacar que la clara de huevo también aparece en otro tratado como remedio para curar el lagrimeo de los perros de caza ${ }^{122}$. En realidad, parece que tanto en el caso de los animales como en el de las personas, no se hacía sino aprovechar las propiedades estípticas atribuidas a estas sustancias $^{123}$.

Una de las sustancias de origen vegetal que en más recetas aparece es la celidonia. Pero López de Ayala prescribía, junto con el coral blanco y la miel, el çumo della para curar las heridas en los ojos de los halcones ${ }^{124}$.

${ }^{121}$ J. Cull, B. Dutton (eds.), Un manual básico, pp. 130-131.

${ }^{122}$ Muhammad b. 'Abd Allāh, Libro de los animales que cazan, p. 232.

${ }^{123}$ En el Lilio de medicina se lee: "pongan de estas cosas estípticas en la frente e en las tímporas como convenga a los particulares, ansí como sangre de drago e acacia e mirra e encienso e clara de huevos e sus semejantes" (J. Cull, B. Dutton (eds.), Un manual básico, p. 134).

${ }^{124}$ Aquí se hace necesaria una aclaración. La virtud de curar los ojos asociada a la celidonia -que recibió su nombre precisamente por la "propiedad" atribuida a las golondrinas de curar la vista o los ojos de sus polluelos con esta planta- fue muy conocida durante la Antigüedad y la Edad Media, y ya se recogía en obras como la Naturalis Historia de Plinio o las Etymologiae de Isidoro de Sevilla. Pero López de Ayala tomó el remedio de Pero Menino quien, para tratar el ojo, recetaba "hũa erva que chamão pipul[el]a e en outra terra lhe chamão bruça pastoril e pizaa" (M.R. Lapa (ed.), Libro de falcoaria, p. 63). El canciller intentó aclarar la identificación añadiendo otro nombre de la planta: "toma una yerva que llaman pinpinela, otros la llaman bursa pastoris, otros la llaman yerva de golondrina" (M. Delgado, Edición crítica, p. 356). Sin embargo, la yerva de golondrina es fácilmente identificable con la celidonia y no lo es, en absoluto, con la pinpinela ni con la bursa pastoris. Por otra parte, un tratado catalán, estrechamente relacionado con ambos textos, resulta mucho más próximo al portugués: "preneu vna erba que ha nom pinpinella en altra manera appellada burca lastoris e picaula be" (Libre de animals de caçar, f. 49v). Así pues, cabe preguntarse si el canciller no introdujo la hierba golondrinera por conocer sus propiedades curativas de los ojos, haciéndola así corresponder con la planta que el autor portugués había recomendado para las heridas oculares. Por otra parte, en el Lilio de medicina se prescribe la bursa pastoris precisamente para la rotura de la córnea y la "yerva que las golondrinas trahen a sus fijos" se identifica en dicha obra, sorprendentemente, con la centidonia en lugar de la celidonia. (J. Cull, B Dutton (eds.), Un manual básico, pp. 136-137). 
En El libro de los caballos se indica tomar los poluos de la çiriduenna e los poluos del estiercol del omne quemado e boluerlo todo en uno, e echar gelos con vn cannuto enel oio ${ }^{125}$, mientras que en el Lilio de medicina aparece como ingrediente en diversas recetas para curar el paño y la comezón en el ojo $^{126}$. También podemos llamar la atención sobre el hecho de que el resto de los ingredientes de la receta para los ojos de las aves que recoge la obra del canciller -coral y miel- aparecen igualmente en diversas recetas para curar enfermedades oculares de los humanos ${ }^{127}$.

La tradición cetrera árabe introdujo en los tratados castellanos de caza un elevadísimo número de sustancias para curar las enfermedades de las aves y de los perros a través del Libro de los animales que cazan, traducción castellana de una obra árabe hoy tan solo conservada parcialmente ${ }^{128}$. Algunas de estas sustancias están prácticamente ausentes de los tratados de albeitería, lo que podría inducir a pensar en una transmisión textual de conocimientos médicos ceñida al ámbito de la caza e independiente de otras tradiciones o prácticas médicas. Entre las sustancias que aparecen como remedio para diversas enfermedades de los ojos de aves y perros se encuentran las cáscaras de los huevos, el azafrán, el oropimente, el espicanardo y la pimienta. Sin embargo, pese a su ausencia de los tratados de albeitería, resulta sencillo comprobar que dicha materia medica se encontraba perfectamente reconocida en los tratados de medicina humana entre los remedios para curar las enfermedades oculares ${ }^{129}$. Pero, además de las ya mencionadas, tres sustancias de origen animal merecen especial atención debido a su presencia exclusiva, como remedio para las enfermedades de los ojos, en los tratados de medicina animal dependientes de la tradición árabe: la hiel (de distintos animales, pero especialmente de aves rapaces), la leche de mujer y la sangre (especialmente de aves) ${ }^{130}$. Estos tres remedios contaron con una larga tradición en la cura de las enfermedades oculares de las aves de presa, pues ya figuran en los tratados árabes de cetrería compuestos entre los siglos VIII

${ }^{125}$ G. Sachs, El libro de los caballos, p. 26.

${ }_{126}$ J. Cull, B. Dutton (eds.), Un manual básico, p. 133.

${ }^{127}$ Ibidem, p. 137.

${ }^{128}$ Esta traducción directa del árabe al castellano, completada en 1250, se produjo de forma independiente de la traducción al latín de otra obra árabe estrechamente relacionada. La traducción latina, realizada en la corte de Federico II y conocida por el nombre latinizado de su autor, Moamin, tuvo gran difusión por Europa. El texto árabe conservado ha sido recientemente editado por A. Akasoy y S. Georges con el título Muhammad ibn 'Abdallāh al-Bāziyār. Das Falken- und Hundebuch des Kalifen al-Mutawakkil.

${ }^{129}$ Pueden encontrarse dichas sustancias entre los remedios para las diferentes enfermedades oculares tratadas en el Lilio de medicina (J. Cull, B. Dutton (eds.), Un manual básico, pp. 129-143).

${ }^{130}$ Muḥammad b. 'Abd Allāh, Libro de los animales que cazan, pp. 196-200 y 231-232. 
y $\mathrm{X}^{131}$ y algunos siguieron prescribiéndose en los tratados castellanos hasta el siglo XVI ${ }^{132}$. Sin embargo, la presencia de estas tres sustancias en numerosas recetas de los tratados de medicina humana sugiere que no se trataba de remedios específicos para las aves de caza sino, más bien, de medicinas perfectamente establecidas para curar las enfermedades de los ojos, tanto de personas como de animales ${ }^{133}$.

Para completar esta rápida revisión de la materia medica contenida en las recetas para curar las enfermedades oculares de los animales, podemos destacar la concha de la sepia ${ }^{134}$, la grasa, el lentisco ${ }^{135}$, el hinojo, la eufrasia y la tutía ${ }^{136}$, observando que se trata, en la mayor parte de los casos, de sustancias bien presentes en las recetas de la medicina huma$\mathrm{na}^{137}$. Entre ellas, el caso de la grasa resulta especialmente interesante, por cuanto sugiere una profunda comprensión de las propiedades de dichas sustancias. En el tratado de albeitería de Manuel Díez, para curar la nube se indica:

E aximateix es molt bo ala dessus dita malaltia que prengau sal ben picada e mesclaulo ab fempta de luert e meteulin dintre los ulls ab un cano buffant: empero no lin metesseu demasiadament car seria perillos de guastarli los ulls E si lo pany o tel era molt antich es mester quel vnteu dos o tres vegades ab greix de gallina: abans que noy metau dita polvora ${ }^{138}$.

${ }^{131}$ La sangre de gorrión se prescribe para la lesión ocular (turfa) en una obra del siglo VIII (F. Viré, D. Möller (eds.), Al-Gitrif ibn Qudāma al-Ġassan̄i, p. 121); la leche de mujer se prescribía para "blancura" del ojo (bayāẹ) en una obra del siglo IX (A. Akasoy, S. Georges (eds), Muhammad ibn 'Abdallāh al-Bāziyār r, p. 60); la hiel de gallo se prescribía para la "blancura" del ojo (bayāẹ) en una obra del siglo x (al-Ḥasan ibn al-Ḥusayn, Al-bayzara, p. 88).

132 J. Vallés, Libro de acetrería, pp. 279-282.

${ }^{133}$ En numerosas recetas del Lilio de medicina se encuentran estas tres sustancias; especialmente frecuente es la leche de mujer (J. Cull, B. Dutton (eds.), Un manual básico, pp. 132-139).

${ }^{134} \mathrm{La}$ concha de la sepia aparece, sobre todo, en los tratados de albeitería para tell, pany o núvol en los ojos: "aja hom del os de sípia, e ros de vi" (J. Gil, Lo cavall, p. 67); en medicina humana se prescribía para la nuve, la manzilla o la cicatriz en la córnea: "pueden de ligero curarse con leche de muger muchas vezes puesta, e después con polvo de huesso de xibia o ansî́" (J. Cull, B. Dutton (eds.), Un manual básico, p. 137).

${ }^{135}$ El lentisco aparece en una receta para el ave "que te tel en lull o desfeta per colp o per als" (Libre de animals de caçar, f. 49r) y en el Llibre de menescalia de Manuel Díez, también aparece para "colp de ull de cauall" (M. Dieç, Tractat, f. 33).

${ }^{136}$ La tutía aparece como remedio para la tela en el ojo en un tratado de cetrería catalán: "meteuli en lull hon tendra lo mal dela tutia que tenen les metgeses dels vlls" (Libre de animals de caçar, f. 49r).

${ }^{137}$ Pueden encontrarse en los capítulos de las enfermedades de los ojos del Lilio de medicina (J. Cull, B. Dutton (eds.), Un manual básico, pp. 129-140).

${ }^{138}$ M. Dieç, Tractat, f. 32r (la cursiva es mía). 
Por otra parte, en el Libre de animals de caçar, tras proporcionar varias recetas para curar las enfermedades de los ojos de las aves, se añade

Item si veyets que ab neguna de aquestes medeçines se milloraua lo oçell ne guarja fets li aquesta medeçina e guarra. preneu greix de guatla e premeu lo be. e de aquell such que exira posaune per lo matj en deju vna gota en lull al oçell ab vna ploma e axi mateix al vespre quant haura pasat la gorga e dauli de bons pasts llexetius com dit es e teniulo en casa scura que no li do ayre e ab aço guarra ${ }^{139}$.

Es decir, la grasa se prescribía cuando la enfermedad era antigua y se hallaba fuertemente asentada, de manera que con los remedios habituales no lograba ser curada. Esta circunstancia concuerda con lo que se presenta en el Lilio de medicina y es que, entre los numerosos remedios para curar las enfermedades de los ojos, se recurre a la enxundia de puerco sólo cuando la mácula fuere endurecida, pues entonces difícilmente o nunca se cura $^{140}$.

\subsection{La sarna y su tratamiento}

El estudio de la sarna en la baja Edad Media, siendo una enfermedad padecida por bestias y hombres, presenta un interés doble en la aproximación a la comprensión de las relaciones entre la medicina humana y la medicina de los animales ${ }^{141}$. En primer lugar, permite introducir en el análisis comparativo, de una forma más significativa, la atención médica prestada a los perros. La literatura medieval sobre el cuidado de los canes es mucho más reducida que la relacionada con los otros grupos de animales que estamos consideran-

${ }^{139}$ Libre de animals de caçar, f. 49v (la cursiva es mía).

${ }_{140}$ J. Cull, B. Dutton (eds.), Un manual básico, pp. 137-138.

${ }^{141} \mathrm{Al}$ igual que en el caso de las enfermedades de los ojos, en este estudio no hemos hecho ningún intento de identificar la enfermedad llamada sarna en los tratados medievales, sean de medicina humana o de medicina animal, con enfermedades modernas, ya que nuestro interés se centra en determinar si los responsables de curar a animales y personas aplicaban remedios semejantes para lo que ellos consideraban que era una misma enfermedad o enfermedades relacionadas. De hecho, con el término sarna, en el presente estudio, nos referimos a un conjunto de enfermedades más o menos relacionadas en los propios tratados, bien porque en ellos se consideraban formas diferentes de una misma enfermedad ("Tiña es sarna de la cabeza", en J. Cull, B. Dutton (eds.), Un manual básico, p. 81), bien porque las consideraban estados en el desarrollo de la enfermedad ("Todas estas postillas si las menospreciaren e no las alimpiaren, convertirse hán en sarna", ibidem, p. 60). Además de estas consideraciones, hemos tenido en cuenta la sinonimia explícita hallada en los propios tratados, de modo que hemos revisado los tratamientos propuestos para las enfermedades nombradas con los términos sarna, postillas, tiña, llaga, tinnuela, tiriola, gales, ronya, escabia, etc. 
do y es que gran parte de la información sobre los cuidados de los perros se encuentra en obras cinegéticas -montería o cetrería- y en ellas los cuidados de estos auxiliares de la caza se presentan solo como un complemento y no como argumento central ${ }^{142}$. En tal situación, la información proporcionada en estas obras sobre los cuidados de los perros es bastante reducida y, en algunos casos, se limita al tratamiento de unas pocas enfermedades o incluso solo una: la sarna ${ }^{143}$. Y es que, a juzgar por la presencia en la literatura medieval, la sarna debía ser una de las enfermedades que con frecuencia padecían, al igual que las personas, las caballerías y los perros, además de bovinos y ovinos domésticos.

En segundo lugar, como ha puesto de manifiesto Michael R. McVaugh, en el siglo XIII se produjo en el Occidente latino una modificación en la distribución de competencias entre médicos y cirujanos. Éste último pasó de ocuparse de los cuidados que requerían una intervención mecánica sobre el paciente -sangrías, cauterios, fracturas y luxaciones, etc.- a atender también aquellas dolencias que se mostraban y se trataban en el exterior del enfermo, entre las que se encuentra la sarna y, en general, todas las enfermedades de la piel $^{144}$. Este traslado de competencias provocó que diferentes aproximaciones terapéuticas, como eran la medicina y la cirugía, se solaparan y propusieran tratamientos distintos para una misma enfermedad. La importancia de este hecho radica en que nos permite afinar más en el conocimiento de las relaciones entre medicina animal y humana medievales al intentar determinar si los tratamientos prescritos para curar las enfermedades de los animales, y en particular la sarna, eran los propios de los cirujanos o de los médicos.

En relación con las causas de la enfermedad, los tratados de caza y de albeitería se refieren, aunque brevemente, tanto a las causas internas o fisiológicas (res naturales) como a las externas (res non naturales). Manuel Díez, en su tratado de albeitería, resumía las causas diciendo que tot aço li ve per sobres de sanch e per males humors: e aximateix li ve al cavall per menjar en loch hon hajen estat gallines ${ }^{145}$. La explicación humoral de la enfermedad coincide, en líneas generales, con la proporcionada en los tratados de medicina humana, si bien en éstos se distinguen diferentes formas de la enfermedad, dependiendo del humor corrupto. Según Bernardo Gordonio

\footnotetext{
${ }^{142}$ Una revisión sobre los tratados medievales de los cuidados de los perros puede verse en B. Van den Abeele, J. Loncke, Les traités médiévaux, pp. 281-296.

${ }^{143}$ Ibidem, Les traités médiévaux, pp. 281-282. En dos tratados catalanes de cetrería se encuentran recetas para la sarna de los perros: Libre de animals de caçar, ff. 90v-91v, y Llibre dels ocells de caça, f. 150r.

${ }^{144}$ M.R. McVaugh, Petrarch's scabies, pp. 53-76.

${ }^{145}$ M. Dieç, Tractat, f. 40r.
} 
La causa d'esta passión son humores corrompidos en el fígado engendrados ... De la sarna son quatro especies, conviene a saber, de sangre, de cólera, de flema salada, e de melancolía ${ }^{146}$.

En cuanto a las causas externas, existe una interesante coincidencia en tratados de albeitería y de caza al señalar el exceso de ejercicio y las condiciones del alojamiento de los animales (dos de las seis res non naturales) como responsables de la enfermedad. El Libre de animals de caçar explica:

Esdeues a vegades que alguns cans dels que hom te pera caça tornen sarnosos per lo molt treball e la set que sostenen en la caça e per ser axi mateix mal provehits e no tenir en lo iuern hon dormen los cans sino en terra e al fret. per que tot c[açad]or deu prouehir be sos cans e tenir los continuament aygua clara dauant en qual que vaell $\mathrm{E}$ axi mateix tenir los tots temps en speçial [en lo hi]uern [en] que dormen ${ }^{147}$.

Mientras que en Lo libre dels cavayls se lee:

Fa.s al cavayls huna enffermetat a qui dien triola o ronya dels travadors, de la qual soffir gran pena, que a vegades com hix del estable no·ls pot plegar per què ranqueja fins que és escalffat, la qual ronya o tryola se fa mes en temps fret que en altre, per rahó de la molta sanch com lo cavayll va per mala carrera e pedregosa e fa masa gran jornada e a la nit meten-lo en estable ab los peus banyats e bragosses e jau en terra dura hon ha pocha palla on no.s pot posar bé per lo trebayll que ha soffert. E per açò com serà calent del caminar com lo meten en l'estable per estes rahons devallen les humors als peus derrerés, e molt més açò en edat de .viij. ans, e aquelles humors consol[d]en e reffreden-se entorn de les junctures de les cames de la ungla fins a la falca, e cové que inflan molt en yvern e en estiu, fan-se ab la inffladura en les costes, en los ronyons, n'àn dolor meyns de ynffladura ${ }^{148}$.

Es de destacar el hecho de que en ambos casos, tanto para los perros como para los caballos, se establezca para la enfermedad una relación causal con el frío y con el invierno, ya que ello coincide con lo que consideraba la medicina humana; de hecho, se pensaba que el calor del verano facilitaba la curación del enfermo ${ }^{149}$. Posiblemente esta idea estuviera en la base de que, para algunas especies de sarna que padecían las personas, se prescribiera que

\footnotetext{
146 J. Cull, B. Dutton (eds.), Un manual básico, p. 58.

${ }^{147}$ Libre de animals de caçar, f. 90v-91r (la cursiva es mía).

${ }_{148}$ J. Gili (ed.), Lo libre dels cavayls, p. 91 (la cursiva es mía).

${ }^{149}$ M.R. McVaugh, Petrarch's scabies, pp. 53-76.
} 
después que el cuerpo fuere purgado, fáganle estufa muchas vezes estando el estómago vazío ${ }^{150}$ antes de aplicar los ungüentos pertinentes. El calor como elemento conveniente o necesario en el tratamiento de la sarna aparece de forma muy clara en varios textos sobre la cura de los animales. En el Libro de los animales que cazan, para curar a los perros de sarna se indica que los fagan estar al sol el día que fizier calentura, antes de untarlos con los ungüentos recomendados ${ }^{151}$. Del mismo modo, en las obras de albeitería también se recomendaba poner los caballos al sol o al calor del fuego antes de aplicar los ungüentos o mientras se realizaba dicha operación ${ }^{152}$.

Además de la exposición al calor, otras dos operaciones se recogen en los tratados medievales para curar la sarna, tanto de animales como de las personas. Con el fin de eliminar los humores corruptos o sobreabundantes responsables de la enfermedad, la sangría era el procedimiento de evacuación más recomendado por albéitares y cazadores, coincidiendo con el empleado por cirujanos para algunas formas de dicha enfermedad en humanos ${ }^{153}$. Manuel Díez, al prescribir esta operación para los caballos advertía de la necesidad de atender a la edad y la fortaleza del animal, algo que no hacía sino seguir las recomendaciones que se establecían para sangrar a las personas ${ }^{154}$.

La otra operación compartida por cirujanos, albéitares y cazadores para librar a sus pacientes o animales de este mal era el baño. En el Lilio de medicina, como en otros tratados de medicina humana, se encuentra el baño entre las recomendaciones para curar diferentes tipos de sarna ${ }^{155}$. Para los caballos, algunos albéitares recomendaban

que lo cavayll plen de gales fins al genol longament de matí e de vespre en aygua freda lo tinga hom, e sia corrent la aygua; açò sia feyt per alguns dies fins que les gales s'estregan e minven per lo costrenyiment de la aygua freda ${ }^{156}$,

${ }^{150}$ J. Cull, B. Dutton (eds.), Un manual básico, p. 60.

${ }^{151}$ Muhammad b. 'Abd Allāh, Libro de los animales que cazan, p. 238. También en el capítulo del tratado de cetrería catalán dedicado a la sarna de los perros, se ordena "exugaulo al sol e vntau lo be al sol ab dit vnguent" (Libre de animals de caçar, f. 91r).

152 J. Gili (ed.), Lo libre dels cavayls, p. 90, M. Dieç, Tractat, ff. 10v-11r.

${ }^{153}$ J. Cull, B. Dutton (eds.), Un manual básico, p. 58.

154 "Sagnau lo cavall dela vena del mitg del coll e traheu li dues o tres liures de sanch: empero mirau la edat del cauall e la força e segons lo estament la sagnia" (M. Dieç, Tractat, f. 10v). En la obra de Alberto Magno, para curar al perro de varias enfermedades de la piel, incluida la sarna, se prescribe la sangría, indicando la vena que se debe sajar (J. Loncke, La Practica canum, p. 105).

${ }^{155}$ J. Cull, B. Dutton (eds.), Un manual básico, p. 59; M.R. McVaugh, Petrarch's scabies, pp. 53-76.

${ }^{156}$ J. Gili (ed.), Lo cavall, p. 83. 
mientras que otros aconsejaban

rabeg-li hom bé les cuxes ab aygua calent per ço que les humors se atempren e s'i asubtillen ${ }^{157}$.

En estos casos, además de prescribir el baño, ambos autores proporcionaron una justificación para dicho tratamiento, explicando el efecto del agua sobre los humores o las costras; ello es un indicio claro de que sus remedios tenían una base racional. También en el caso de los perros, el baño se indicaba en combinación con algunas medicinas, como ungüentos o polvos:

échenles de los polvos sobre la sarna e déxenlas estar assí es día que gelo fizieren, e después méta[n]los en el banno e lávenlos con agua tibia, e después que los aduxieren del banno pora sus posadas, lávenlos otra vez con agua calient atal que la puedan sofrir, e después que se enxugaren, úntenlos con azeit e échenles otra vegada de los polvos que dixiemos ${ }^{158}$

Así pues, la aplicación de calor, la sangría y los baños eran tres operaciones ampliamente reconocidas en los tratados de medicina, albeitería y de caza como remedio para curar la sarna de personas, caballos y perros respectivamente. En el caso de los animales, estas tres operaciones complementaban el tratamiento más importante, que consistía en la aplicación de ungüentos en las zonas afectadas por la enfermedad. Pese a que la medicina humana contaba con remedios para curar la sarna basados en la dieta y en la ingestión de medicinas y purgantes (prescripciones más propias de los médicos), éstos se encuentran prácticamente ausentes en las múltiples recetas que se han conservado para curar la enfermedad en perros y caballos. Del gran número de sustancias que, en conjunto, constituyen la materia medica de las recetas contra la sarna, prácticamente todas están orientadas, como se ha señalado, a la preparación de ungüentos (sustancias preparadas, esencialmente, para curar enfermedades de la piel, especialidad de la cirugía desde el siglo XIII). Esto nos permite conjeturar que albéitares y cazadores pudieron tener más relación con cirujanos que con médicos. En apoyo de esta suposición tenemos las diversas referencias a los cirujanos en los tratados de caza con aves. Pero López de Ayala, en su tratado de cetrería, en varias ocasiones recomendaba la ayuda o supervisión de un cirujano para realizar alguna cura a las aves ${ }^{159}$, además de

\footnotetext{
157 J. Gili (ed.), Lo libre dels cavayls, p. 92.

${ }^{158}$ Muḥammad b. 'Abd Allāh, Libro de los animales que cazan, p. 238

${ }^{159}$ M. Delgado, Edición crítica, pp. 352, 365 y 398.
} 
precisar, a menudo, que determinadas sustancias necesarias para tratarlas eran las que poseían o empleaban los cirujanos ${ }^{160}$.

De cualquier modo, al igual que en el caso de los remedios para las enfermedades oculares, también las sustancias empleadas para preparar los ungüentos curativos de la sarna en perros y caballos coinciden con las que recogían los tratados de medicina humana. El mercurio (azogue o argento vivo) y el azufre eran, sin duda, las dos sustancias más empleadas como ingredientes de estos ungüentos para animales, seguidas por otras como la cal, el albayalde, el oropimente, el litargirio o el alumbre. Estas sustancias concuerdan, en gran medida, con las que McVaugh halla en las recetas de la obra de Teodorico Borgognoni para curar la sarna en humanos ${ }^{161} \mathrm{y}$, al igual que lo observado por el investigador, la grasa constituía el principal elemento con el que mezclar las mencionadas sustancias para la preparación del ungüento. Otras sustancias menos frecuentes o que aparecen en una única receta para perros o caballos pueden igualmente encontrarse entre las fórmulas de los ungüentos o preparados de la medicina humana; tal es el caso de las heces de vino $^{162}$, la adelfa ${ }^{163}$ o la alheña ${ }^{164}$.

También en las recetas para curar la sarna encontramos semejanzas importantes en las formas de preparación. Un caso interesante, en este sentido, lo proporciona el mercurio o argento vivo que, según algunas recetas, debía

${ }^{160}$ Ibidem, pp. 325, 331, 333 y 394.

${ }^{161}$ M.R. McVaugh, The Rational Surgery, p. 146: "many of his ointments against scabies are based on strong chemicals: cerusa, litharge, sulphur, arsenic, and above all mercury, typically mixed with oil or fat and rubbed onto the affected skin".

${ }^{162}$ Es interesante observar que las recetas para caballos y para personas coinciden en otros ingredientes, además de las heces de vino (ros de bóta en catalán): "para llagas en la cabeza: toma fezes del vjno e quemalos e muelas con vna poca de cal e amasalo con vinagre" (J. Cull, B. Dutton (eds.), Un manual básico, p. 33); "feuli lo seguent enguent Preneu soffre viu: e sal: e ros de bota e picau ho tot fort y mesclau tot ab vinagre que sia fort e ab oli tant de la hu com del altre: e passauho tot fins que sia espes axi com enguent" (M. Dieç, Tractat, f. 40v).

${ }^{163}$ La preparación de la adelfa presenta semejanzas importantes en recetas para personas y para animales. En el Tratado de patología se prescribe "otra vntura que presta a la sarna vmjda e prouada: toma adelfa uerde e cuezelo en agua e cuelalo e buelue con ello çera bermeja e azeyte" (M.T. Herrera, M.N. Sánchez (eds.), Tratado de patología, p. 39.). Esta receta coincide, en diversos aspectos de la preparación, con la del tratado de albeitería de Manuel Díez que incluye la misma planta entre sus ingredientes: "Preneu fulles de baladre que sien fresques e meteules en una olla nova plena de aygua e bulliu ho tant fins que la aygua torn ala terça part e apres lançau ne les fulles e preneu sagi de porch que no sia salat e soffregiu lo a lançau ne la cremadura e preneu cera nova blanca e lo brou del baladre e meteu ho tot en una cassola e bulliu ho fort: e quant haura molt bullit levauho del foch e dexau ho refredar." (M. Dieç, Tractat, f. 50v).

164 "e tome pelitre e alfenna e aristologia e litargirio e cortezas de mjelgranas e muelenlo todos; amasenlo con vinagre fuerte e con olio rosado e vnten con ello la cabeça" (M.T. Herrera, M.N. Sánchez (eds.), Tratado de patología, pp. 35-36); "Preneu dues onses de argent viu: e dues de sofre: e una liura dalquena: e una liura de oli: e altretant vinagre: e una liura de mel: e tot aço sia ben mesclat axi com enguent: e meteu lo cavall al sol e untau lo fort" (M. Dieç, Tractat, f. 40r). 
ser amatado o mortificado durante la preparación de la medicina. Así se explica en la Suma de la flor de cirugía: vnto de puerco ritido al fuego .j. onça argen byvo e mortificado con salyva ayuna ${ }^{165}$. El procedimiento de utilizar saliva para matar el mercurio es semejante al contenido en la receta contra la sarna de los perros, que explica: preneu vna onça de argent viu e posaula en vna scudelleta e scopiuhi saliua e desfeu ab lo dit e ab la saliua lo argent $v i u^{166}$. Sin embargo, aún es más próximo al que explica la obra de Manuel Díez en otra receta, pues en ella se precisa que se debe tomar argent viu esmortit ab saliua dejuna de home ${ }^{167}$.

\section{CONCLUSIONES}

El estudio de los tratados bajomedievales hispánicos que contienen información sobre los cuidados de caballos, perros y aves de caza, animales todos de gran valor económico y social en la baja Edad Media, permite constatar numerosas relaciones con los contenidos de las obras medievales de medicina humana. Estas relaciones abarcan prácticamente todos los aspectos de la vertiente doctrinal de la disciplina. Más allá de las referencias a los humores o cualidades que aparecen en los tratados de albeitería y de caza, y que ya han sido puestas de manifiesto en diversos estudios sobre la medicina animal en la Edad Media, el recurso a otros conceptos, principios y contenidos del galenismo para explicar todo lo relacionado con la salud y la enfermedad de los animales es mucho más amplio y, pese a que no siempre fue explícito, sí fue coherente con la doctrina médica.

La importancia atribuida a la complexión de los animales a la hora de establecer el régimen higiénico -o los remedios, en caso de enfermedad- está en la base de algunas prescripciones de los tratados de caza y albeitería. Del mismo modo que los hábitos y costumbres del paciente debían ser tomados en consideración en los regímenes o tratamientos para humanos, en las prescripciones para los animales tampoco se debía ignorar el régimen al que éstos se habían acostumbrado. La explicación de las enfermedades como corrupción de humores, exceso de alguno de ellos o acumulación de los mismos o de superfluidades en determinados lugares del cuerpo concuerda plenamente con las causas halladas en los tratados de medicina humana. Que las enfermedades pasaban por diferentes estadios y que podían transformarse en otras -normal-

${ }^{165}$ De la obra Suma de la flor de cirugía, citado en M.T. Herrera (dir.), Diccionario español de textos médicos antiguos, p. 145.

${ }^{166}$ Libre de animals de caçar, $\mathrm{f} .91 \mathrm{r}$.

${ }^{167}$ M. Dieç, Tractat, f. 20r. 
mente de más difícil tratamiento- cuando no eran curadas, es algo de lo que eran igualmente conscientes los médicos, los albéitares y los cazadores.

El papel destacado de la salud y su conservación sobre la enfermedad y su cura es otro aspecto en el que los tratados de medicina animal y humana coincidieron claramente y que se plasmó, a partir del siglo XIII, en la proliferación de los regimina sanitatis como género literario médico por una parte y, por otra, en la ampliación de los contenidos de los tratados de albeitería y de caza (especialmente de cetrería) para dar cabida a los preceptos orientados a conservar la salud de los animales y evitar la enfermedad. En ambos casos, los aspectos regulados por el régimen fueron aquellos que el galenismo había agrupado en las seis res non naturales, pese a que en las obras sobre los cuidados de los animales no se hiciera referencia explícita a esta ordenación de la doctrina médica. En tales casos, breves referencias a los conceptos galénicos, junto con prescripciones idénticas a las halladas en los regímenes de salud humanos, sugieren que la doctrina galénica estaba detrás de los regímenes higiénicos de los animales, si bien no pueden descartarse razones empíricas para determinadas indicaciones dietéticas. Por otra parte, factores como complexión, edad, época del año y otras circunstancias fueron tenidas en consideración por cazadores y albéitares, al igual que por médicos, a la hora de establecer los regímenes.

Con plena conciencia del efecto negativo que los medicamentos tenían sobre el organismo, una vez que el animal estaba afectado por la enfermedad, los cuidadores aconsejaban curarlo con los remedios menos contrarios y que menos dañaran el cuerpo del mismo, dando prioridad a la dieta sobre las medicinas. Purgantes, sangrías y cauterios fueron técnicas ordenadas para evacuar humores o superfluidades de animales y personas. El principio de "curar por el contrario" subyace en algunos tratamientos descritos para los animales, si bien las cualidades o complexiones de los simples no agotaban las propiedades curativas de los mismos, observándose en numerosas recetas el recurso a las propiedades específicas -especialmente las secundarias- de dichas medicinas para curar diversas enfermedades, algo habitual en medicina humana.

El valor del examen de las superfluidades producidas por el cuerpo de los animales para determinar el estado de salud de los mismos o diagnosticar sus enfermedades fue algo que destacaron los halconeros encargados del cuidado de las aves de caza, de forma muy similar a lo que hicieron los médicos medievales con las superfluidades del cuerpo humano, especialmente la orina.

El esquema expositivo de las enfermedades de los animales también fue evolucionando a partir de lo que podrían ser meras recopilaciones de recetas para aproximarse cada vez más a la estructura de los tratados médicos, 
con una exposición que intentaba ordenar las enfermedades según el modelo $a$ capite ad calcem y explicando, para cada una de ellas, las causas, las señales y la cura. Esta última sección, en la que se fueron acumulando múltiples recetas que integraban, en conjunto, una vastísima materia medica, es quizá la que nos permite más fácilmente constatar la estrecha relación entre la medicina animal y humana, ya que prácticamente todas las sustancias contenidas en dichas recetas pueden encontrarse entre los remedios, para los mismos males, de los tratados médicos.

Dado el carácter eminentemente práctico que se atribuye a los tratados de albeitería y cetrería, en dichas obras se prescindió de reflexiones o argumentaciones teóricas complejas o extensas, lo que no quiere decir que no existiera una base racional para los contenidos expuestos. Dicha base se hace visible al comparar los contenidos de las obras de medicina de los animales con las de medicina humana y aquellas entre sí. Y es que este análisis conjunto permite también encontrar importantes coincidencias y relaciones significativas entre los cuidados de los perros, los caballos y las aves.

Todo ello sugiere que una "relectura galénica" minuciosa de los textos medievales sobre la cura de los animales, especialmente aves, perros y caballos, permitiría comprender adecuadamente muchos pasajes, que cobrarían pleno sentido al ser interpretados en el contexto doctrinal del galenismo. La ampliación del ámbito de estudio a los textos de medicina animal del resto del Occidente latino, así como la incorporación de los tratados árabes constituiría el marco adecuado para estudiar la formación y evolución de la doctrina médica asociada al cuidado de los animales. Esta línea de investigación se vería muy favorecida por la edición crítica de los numerosos manuscritos de cetrería y albeitería que aún permanecen inéditos.

Por otra parte, los avances en este campo de investigación serán de gran utilidad para el estudio de la vertiente práctica del cuidado de los animales y la evaluación de su mayor o menor correspondencia con los preceptos doctrinales recogidos en los tratados, así como los aspectos sociales, tales como la transmisión de conocimientos, la formación de los cuidadores y su papel en la sociedad bajomedieval.

\section{BIBLIOGRAFÍA CITADA}

Abalo Buceta, José María, Livro da Montaria de D. João I de Portugal, Valladolid, Universidad de Valladolid, 2008 (tesis doctoral inédita).

Akasoy, Anna; Georges, Stefan (eds), Muhammad ibn 'Abdallāh al-Bāziyār. Das Falken- und Hundebuch des Kalifen al-Mutawakkil, Berlín, Akademie Verlag, 2005. 
'Alī ibn al- 'Abbās al-Maŷūsī, Liber Pantegni, 1515, en Wolfenbütel Digital Library: http://diglib.hab.de/drucke/ma-4f-35/start.htm?image $=00470$ [consulta: 20/09/2012].

al-Baladī, 'Abd al-Raḥmān b. Muḥammad, Kitāb al-kāfí fí al-bayzara, 'Abbās, Iṇsān; Manșūr, 'Abd al-Ḥafìz (eds.), Beirut, Al-mu'assasa al'arabiyya li-l-dirāsāt wa-l-našr, 1984 (en árabe).

Cifuentes, Lluís; Ferragud Domingo, Carmel, El 'Libre de la Menescalia' de Manuel Dies: de espejo de caballeros a Manual de Albéitares, "Asclepio" 51 (1999), pp. 93-127.

Cull, John; Dutton, Brian (eds.), Un manual básico de medicina medieval. Bernardo Gordonio. Lilio de medicina, Madison, The Hispanic Seminary of Medieval Studies, 1991.

Czapalla, Hellmut. Die Falkenheilkunde des kurfürstlichen Amtmannes Johann Wolff aus Mündelsheim (1584), Berlín, Tierärztliche Hochshule zu Berlin, 1936 (tesis doctoral).

Delgado Montoto, Manuel, Edición crítica del 'Libro de la caza de las aves' de Pero López de Ayala, Madrid, Calasancias, 2007.

Dieç, Manuel, Tractat fet per lo Magnifich mossen Manuel Dieç, Barcelona, Dimas Ballester y Joan Giglo, 1523.

Driesch, Angela von den; Peters, Joris, Geschichte der Tiermedizin. 5000 Jahre Tierheilkunde, Stuttgart, Schattauer, 2003.

Faraudo de Saint-Germain, Luis (ed.), El texto primitivo inédito del "Tractat de les mules" de Mossén Manuel Dieç, "Boletín de la Real Academia de Buenas Letras de Barcelona" 22 (1949), pp. 23-62.

Ferragud Domingo, Carmel, La cura dels animals. Menescals i menescalia a la València medieval, Catarroja, Afers, 2009.

Ferragud Domingo, Carmel, La atención médica de los animales durante la Baja Edad Media en los reinos hispánicos, "Medievalismo" 21 (2011), pp. 29-54.

Fradejas Rueda, José Manuel (ed), Antiguos tratados de cetrería castellanos, Madrid, Caïrel, 1985.

Fradejas Rueda, José Manuel, Literatura cetrera de la Edad Media y el Renacimiento español, Londres, Queen Mary and Westfield College, 1988.

Fradejas Rueda, José Manuel (ed.), Don Juan Manuel y el 'Libro de la caza', Tordesillas, Universidad de Valladolid, 2001.

Fradejas Rueda, José Manuel (ed.); Garcia Sempere, Marinela; Van den Abeele, Baudouin (cols.), Tratados de cetrería catalanes (siglo XIV), Madrid, Círculo de Bibliofilia Venatoria, 2008.

García Ballester, Luis, La búsqueda de la salud. Sanadores y enfermos en la España medieval, Barcelona, Península, 2001. 
Gerdessen, Antje, Beitrag zur Entwicklung der Falknerei und der Falkenheilkunde, Hannover, Tierärztliche Hochshule Hannover, 1956, (tesis doctoral).

Gili, Joan (ed.), Lo cavall. Tractat de manescalia dels segle XV, Oxford, The Dolphin Book Co, 1985.

Gili, Joan (ed.), Lo libre dels cavayls, Oxford, The Dolphin Book Co, 1988.

Gil-Sotres, Pedro, Regimen sanitatis ad regem Aragonum: Introducción, en García Ballester, Luis; McVaugh, Michael R. (eds.), Regimen sanitatis ad regem Aragonum. Arnaldi de Vilanova Opera Medica Omnia. X.1, Barcelona, Universitat de Barcelona - Fundació Noguera, 1996, pp. 471-904.

Gil-Sotres, Pedro, Tractatus de consideracionibus operis medicine sive de flebotomia: Introducción, en Demaître, Luke (ed.), Tractatus de consideracionibus operis medicine sive de flebotomia, Barcelona, CSIC - Universitat de Barcelona, 1998, pp. 7-120.

González Dopazo, Olaya, Libro de albeytería: transcripción, en Díeç, Manuel, Libro de albeitería, Somonte-Cenero, Trea, 2009.

Heinemeyer, Wilhelm, Die Pferdeheilkunde des Bischofs Theodoric von Cervia, Berlín, Friedrich-Wilhelms-Universität in Berlin, 1936, (tesis doctoral).

Herrera, María Teresa (dir.), Diccionario español de textos médicos antiguos, Madrid, Arco/Libros, 1996.

Herrera, María Teresa; Sánchez, María Nieves (eds.), Tratado de patología, Madrid, Arco/Libros, 1997.

al-Ḥasan ibn al-Husayn, Abū 'Abd Allāh (atribuido), Al-bayzara, Muḥammad Kurd 'Alī (ed.), Damasco, Maṭbu 'āt al-ğam' al- 'ilmī al-'arabī, 1953 (en árabe).

Kraenner, Paul, Falkenheilkunde, Berlín, Tierärztliche Hochshule zu Berlin, 1925, (tesis doctoral).

Lapa, Manuel Rodrigues (ed.), Livro de falcoaria, Coimbra, Universidade de Coimbra, 1931.

Libre de animals de caçar, Valencia, Biblioteca Histórica de la Universidad de Valencia, Ms. 505.

Lignereux, Yves, Les soins vétérinaires aux chevaux au Moyen Âge, en Mousnier Mireille (ed.), Les animaux malades en Europe occidentale (VIeXIXe siècle), Tolosa, Presses universitaires du Mirail, 2005, pp. 41-55.

Llibre dels ocells de caça, Barcelona, Universidad de Barcelona, Ms. 68, ff. $108 \mathrm{v}-150 \mathrm{v}$.

Loncke, Jérémy, La Practica canum - Le De cane d'Albert le Grand. L'art de soigner les chiens de chasse au Moyen Âge, Nogent-le-Roi, Jacques Laget, 2007. 
McVaugh, Michael R. (ed.), Aphorismi de gradibus, Barcelona, Universidad de Barcelona, 1975.

McVaugh, Michael R. (ed.), Tractatus de intentione medicorum, Barcelona, Fundació Noguera, 2000.

McVaugh, Michael R., Petrarch's scabies, en Berté, Monica; Fera, Vincenzo; Pesenti, Tiziana (eds.), Petrarca e la Medicina, Messina, Centro Interdipartimentales di Studi Umanistici, 2006, pp. 53-76.

McVaugh, Michael R., The Rational Surgery of the Middle Ages, Florencia, Sismel, 2006.

Mercader, Matías, Pratica de citreria breve, Biblioteca Nacional, Ms. Res/179, en http://bdh.bne.es/bnesearch/detalle/2682764 [consulta: 07/03/2012].

Möckel, Karl-Heinz, Die Pferdeheilkunde des Cosimo Marci Medici, Berlín, Friedrich-Wilhelms - Universität in Berlin, 1938, (tesis doctoral).

Muḥammad ibn 'Abd Allāh ibn 'Umar al-Bayzār (Moamin), Libro de los animales que cazan, Fradejas Rueda, José Manuel (ed.), Madrid, Casariego, 1987.

Paavilainen, Helena M., Medieval Pharmacotherapy, Continuity and Change, Leiden, Brill, 2009.

Poulle-Drieux, Yvonne, L'hippiatrie dans l'Occident latin du XIIIe au XVe siècle, en Beaujouan, Guy; Poulle-Drieux, Yvonne; Dureau-Lapeyssonie, Jeanne Marie (eds.), Médécine humaine et vétérinaire à la fin du Moyen Âge, Ginebra, Droz, 1966.

Poulle-Drieux, Yvonne, Pratique de l'hippiatrie à la fin du Moyen Âge, en Comprendre et maîtriser la nature au Mogen Âge. Mélanges d'histoire des sciences offerts à Guy Beaujouan, Ginebra, Droz, 1994, pp. 329-336.

Poulle-Drieux, Yvonne, La médecine des chevaux ou «Marechalerie» dans l'Occident latin au Moyen Âge, "Bulletin de la Société Française d'Histoire de la Médecine et des Sciences Vétérinaires" 7 (2007), pp. 4-25.

Rico Martín, Ana María (ed.), 'Libro de las aves que cazan' de Juan de Sahagún: edición crítica. Madrid, UNED, 1997, (tesis doctoral en microficha).

Rocabertí, Llibre de cetreria, Ms. privado (ed. facsímil, Barcelona, [s.e.], 1951).

Roth, Robert, Die Pferdeheilkunde des Jordanus Ruffus, Berlín,Tierärztliche Hochshule zu Berlin, 1928, (tesis doctoral).

Sachs, Georg, El libro de los caballos. Tratado de albeitería del siglo XIII, Madrid, Centro de estudios históricos, 1936.

Sanz Egaña, Cesáreo, Historia de la veterinaria española. Madrid, EspasaCalpe, 1941. 
Sanz Egaña, Cesáreo, Noticias de la medicina de los animales de la España cristiana de la Edad Media, Madrid, [s. n.], 1935.

Smets, An, Aux origines de la médecine vétérinaire: le traité d'autourserie de Grimaldus et sa pharmacopée, "Médiévales" 36 (1999), pp. 145-157.

Tilander, Gunnar, Uma tradução portuguesa desconhecida do tratado de cetreria do rei Dancus, "Boletim de Filologia" 6 (1940), pp. 439-457.

Tilander, Gunnar, Dancus Rex, Guillelmus Falconarius, Gerardus Falconarius. Les plus anciens traités de fauconnerie de l'Occident, publiés d'après tous les manuscrits connus, Lund, C. Bloms, 1963.

Vallés, Juan, Libro de acetrería y montería, José Manuel Fradejas Rueda (ed.), Madrid, Círculo de Bibliofilia Venatoria, 1994.

Van den Abeele, Baudouin, La fauconnerie au Moyen Âge: connaissance, affaitage et médecine des oiseaux de chasse d'après les traités latins, París, Klincksieck, 1994.

Van den Abeele, Baudouin; Loncke, Jérémy, Les traités médiévaux sur le soin des chiens: une littérature technique méconnue, en Kranz, Horst; Falkenstein, Ludwig (eds.), Inquirens subtilia et diversa. Dietrich Lohrmann zum 65. Geburtstag, Aquisgrán, Shaker Verlag, 2002, pp. 281-296.

Viré, François (trad.), Le traité de l'art de la volerie (Kitāb al-bayzarah) rédigé vers 385/995 par le Grand-Fauconnier du calife fätimide al-'Azīz bi-llāh, Leiden, Brill, 1967 [publicado previamente en "Arabica" 12 (1965), pp. 1-26, 113-139, 262-296 y 13 (1966), pp. 39-76].

Viré, Fraçois; Möller, Detlef (eds.), Al-Gittrif ibn Qudāma al-Ġassanī (VIIIe siècle). Traité des oiseaux de vol (Kitāb dawārī at-tayr), Nogent-leRoi, Jacqes Laget, 2002.

Fecha de recepción del artículo: noviembre 2012

Fecha de aceptación y versión final: mayo 2013 